\title{
A global modeling study on carbonaceous aerosol microphysical characteristics and radiative effects
}

\author{
S. E. Bauer ${ }^{1,2}$, S. Menon ${ }^{3}$, D. Koch ${ }^{1,2}$, T. C. Bond ${ }^{4}$, and K. Tsigaridis ${ }^{1}$ \\ ${ }^{1}$ NASA Goddard Institute for Space Studies, New York, NY, USA \\ ${ }^{2}$ The Earth Institute, Columbia University, New York, NY, USA \\ ${ }^{3}$ Lawrence Berkeley National Laboratory, Berkeley, CA, USA \\ ${ }^{4}$ University of Illinois, Urbana-Champaign, IL, USA
}

Received: 20 January 2010 - Published in Atmos. Chem. Phys. Discuss.: 15 February 2010

Revised: 5 July 2010 - Accepted: 26 July 2010 - Published: 10 August 2010

\begin{abstract}
Recently, attention has been drawn towards black carbon aerosols as a short-term climate warming mitigation candidate. However the global and regional impacts of the direct, indirect and semi-direct aerosol effects are highly uncertain, due to the complex nature of aerosol evolution and the way that mixed, aged aerosols interact with clouds and radiation. A detailed aerosol microphysical scheme, MATRIX, embedded within the GISS climate model is used in this study to present a quantitative assessment of the impact of microphysical processes involving black carbon, such as emission size distributions and optical properties on aerosol cloud activation and radiative effects.

Our best estimate for net direct and indirect aerosol radiative flux change between 1750 and 2000 is $-0.56 \mathrm{~W} / \mathrm{m}^{2}$. However, the direct and indirect aerosol effects are quite sensitive to the black and organic carbon size distribution and consequential mixing state. The net radiative flux change can vary between -0.32 to $-0.75 \mathrm{~W} / \mathrm{m}^{2}$ depending on these carbonaceous particle properties at emission. Taking into account internally mixed black carbon particles let us simulate correct aerosol absorption. Absorption of black carbon aerosols is amplified by sulfate and nitrate coatings and, even more strongly, by organic coatings. Black carbon mitigation scenarios generally showed reduced radiative fluxeswhen sources with a large proportion of black carbon, such as diesel, are reduced; however reducing sources with a larger organic carbon component as well, such as bio-fuels, does not necessarily lead to a reduction in positive radiative flux.
\end{abstract}

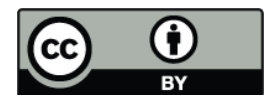

Correspondence to: S. E. Bauer (sbauer@giss.nasa.gov)

\section{Introduction}

Anthropogenic and natural aerosols impact the Earth's radiation balance and thus exert a forcing on global climate. Black carbon (BC) has a positive radiative forcing, whileother aerosol species mainly lead to atmospheric cooling. Therefore cleaning up most aerosol emissions, which is much needed due to their severe health impacts, could strengthen the global warming trend. However, mitigation of $\mathrm{BC}$ has the potential to be beneficial in mitigating both climate warming and air pollution. Emission reductions that target light-absorbing aerosol might also reduce warming quickly (Hansen et al., 2000; Jacobson, 2002; Bond and Sun, 2005). However, BC's indirect (cloud microphysics) and semi-direct contributions to net climate forcing remain an outstanding uncertainty. For example, the model study of Penner et al.. (2003) suggested that "smoke" did not produce net warming, considering both direct and cloud effects. In addition, model experimental results are very sensitive to treatment of aerosol microphysics.

The aerosol direct effect (ADE) is caused by absorption and scattering of solar radiation by liquid and solid aerosol particles in the atmosphere. Strongly absorbing, and therefore enhancing climate warming, are black carbon (BC) particles. The mass absorption strength and scattering ability of a BC particle strongly depends on the particle effective size and mixing state. Both of those quantities depend on the size and chemical composition of black carbon as it is released into the atmosphere as well as its microphysical and chemical evolution during transport through the atmosphere. Most other aerosol species scatter radiation back to space, such as sulfate, nitrate, organic carbon (although some organics can be slightly absorbing), sea salt, aerosol water and to a

Published by Copernicus Publications on behalf of the European Geosciences Union. 
certain extent mineral dust, and therefore these counterbalance climate warming, by cooling the atmosphere. However, if $\mathrm{BC}$ is mixed with these scattering components, the result is enhanced absorption. Laboratory studies by Khalizov et al. (2009) showed that for soot particles with an initial mobility diameter of $320 \mathrm{~nm}$ and a $40 \% \mathrm{H}_{2} \mathrm{SO}_{4}$ mass coating fraction, absorption and scattering are increased by 1.4 - and 13 fold at $80 \% \mathrm{RH}$, respectively. Also, the single scattering albedo of soot aerosol increases from 0.1 to 0.5 after coating and humidification. Jacobson [2000] performed global simulations with core-shell treatment and found BC forcings $50 \%$ higher and $40 \%$ lower than forcings obtained with externally mixed and well-internally mixed treatments, respectively. Therefore, correct treatment of the aerosol size and mixing state is crucial in order to calculate their net radiative forcing.

Attempts to quantify the aerosol direct radiative forcing, the difference in top of the atmosphere forcing between present day and pre-industrial conditions, by the AeroCom initiative gave estimates between -0.41 and $+0.04 \mathrm{~W} / \mathrm{m}^{2}$ [Schulz et al. 2006] and by the IPCC AR4 report a range from -0.9 to $-0.1 \mathrm{~W} / \mathrm{m}^{2}$ [IPCC, 1007]. The wide range of uncertainty is caused on the one hand by large discrepancies among the model systems, ranging from emission strength, transport, aerosol transformation, removal and optical properties. However, the models are also poorly constrained by limited availability of aerosol measurements. Furthermore, Myhre (2009) explains large deviations between models and satellite retrieved forcing estimates by the lack of considering correct pre-industrial aerosol distributions in the satellite data derived forcing calculations and in failure to sample the model like the retrieval.

The aerosol indirect effect (AIE) is caused by an increase in the number of hygroscopic aerosols, with a corresponding increase in cloud droplet number concentrations, reduction in cloud droplet size, increase in cloud albedo (first indirect effect) and suppression of precipitation and increased cloud life time (second indirect effect), thereby cooling the planet (IPCC, 2007). The role of BC in determining cloud droplet number concentrations (CDNC) is unknown [Adams and Seinfeld, 2003], as it depends upon the size distribution and mixing state of $\mathrm{BC}$ with soluble species such as sulfate, nitrate and organic carbon. Furthermore, insoluble black carbon or dust aerosols can act as ice nuclei and therefore alter cirrus and mixed-phase clouds; however these effects are poorly known (e.g. Lohmann et al., 2008). Here again the microphysical evolution of the aerosol population in terms of size and mixing state is crucial in order to identify the number of particles are suitable for cloud activation. The IPCC AR4 report estimates the aerosol indirect radiative forcing (AIF) to lie between -1.8 and $-0.3 \mathrm{~W} / \mathrm{m}^{2}$. The AeroCom initiative, linking models to satellite-based estimates gives a range of $-0.7 \pm 0.5 \mathrm{~W} / \mathrm{m}^{2}$ for the AIF[Quaas et al. 2009]. The models on which these estimates were based generally did not include sophisticated treatment of aerosol mixing state, and the contribution of $\mathrm{BC}$ mixing to the $\mathrm{AIF}$ uncertainty was not evaluated.

In this study we are particularly interested in the microphysical evolution of black carbon. The size and mixing state of carbonaceous particles at emission must be assumed for this investigation. Once emitted, BC can grow by coagulation and condensation. Although freshly emitted pure $\mathrm{BC}$ is hydrophobic, inorganic and organic coatings will attract water and convert particles to be hygroscopic. Materials likely to condense on a $\mathrm{BC}$ particle, as on any other particle, are sulfate and nitrate precursors as well as secondary organics (Riemer et al. 2009). In addition to surface condensation processes, coagulation is a very effective mixing pathway. In the atmosphere every aerosol shape is unique, complex and not necessarily spherical. Transmission electron microscopy (TEM) images support the theory that BC particles become coated once emitted. Although BC may be internally mixed with other components, BC cannot be 'well-mixed' (diluted) in the particle, since soot, which contains BC, is irregularly shaped and mostly solid. Thus most likely BC is distinct and not well mixed within particles.

As we explore the role of $\mathrm{BC}$ in aerosol forcing we will study the following questions:

How important is the size distribution of carbonaceous particles at emission time for the overall aerosol simulation (Sect. 3)? How well can we constrain our model with observational data (Sect. 4)? And how well can we assess BC reduction strategies given the previously discussed microphysical modeling uncertainties (Sect. 5)?

This paper is linked to a study by Menon et al. (2010) (hereafter referred to as SM10) where the same model version and configuration as in this study is used, but the analysis is more detailed with respect to the AIE. SM10 includes evaluation and comparison of the performance of anew AIE scheme coupled to aerosol microphysics or to the previous mass based GISS aerosol model (Koch et al., 2006; Menon and Rotstayn, 2006).

\section{Model description}

The Goddard Institute for Space Studies (GISS) General Circulation Model (GCM) climate modelE (Hansen et al., 2005; Schmidt et al., 2006) coupled to the aerosol microphysics and chemistry model MATRIX (Multiconfiguration Aerosol TRacker of mIXing state) (Bauer et al., 2008), hereafter BA08, is used in this study. MATRIX is designed to support model calculations of the direct and indirect effect and permit detailed treatment of aerosol mixing state, size and aerosol-cloud activation.

MATRIX is based on the quadrature methods of moments (QMOM). MATRIX is under development to use the full advantage of the QMOM scheme (McGraw 1997). In its current version MATRIX includes two moments, number and mass, and one quadrature point. Carrying only two moments 
Table 1. Populations, constituents, and possible particle mixing state considerations in the radiation calculations: homogeneously internally mixed (HI), externally mixed (EM).

\begin{tabular}{|c|c|c|c|}
\hline population description & symbol & constituents & $\begin{array}{l}\text { mixing state options for the coupling } \\
\text { between aerosols and radiation }\end{array}$ \\
\hline sulfate Aitken mode & AKK & $\mathrm{SO}_{4}^{-2}, \mathrm{NO}_{3}^{-}, \mathrm{H}_{2} \mathrm{O}$ & $\mathrm{EM} / \mathrm{HI}$ \\
\hline sulfate accum. mode & ACC & $\mathrm{SO}_{4}^{-2}, \mathrm{NO}_{3}^{-}, \mathrm{H}_{2} \mathrm{O}$ & $\mathrm{EM} / \mathrm{HI}$ \\
\hline dust accum. mode ( $\leq \% 5$ inorg.) & DD1 & dust, $\mathrm{SO}_{4}^{-2}, \mathrm{NO}_{3}^{-}, \mathrm{H}_{2} \mathrm{O}$ & EM \\
\hline dust accum. mode ( $>\% 5$ inorg.) & DS1 & dust, $\mathrm{SO}_{4}^{-2}, \mathrm{NO}_{3}^{-}, \mathrm{H}_{2} \mathrm{O}$ & $\mathrm{EM} / \mathrm{HI}$ \\
\hline dust coarse mode ( $\leq \% 5$ inorg.) & DD2 & dust, $\mathrm{SO}_{4}^{-2}, \mathrm{NO}_{3}^{-}, \mathrm{H}_{2} \mathrm{O}$ & EM \\
\hline dust coarse mode ( $>\% 5$ inorg.) & DS2 & dust, $\mathrm{SO}_{4}^{-2}, \mathrm{NO}_{3}^{-}, \mathrm{H}_{2} \mathrm{O}$ & $\mathrm{EM} / \mathrm{HI}$ \\
\hline sea salt accum. mode & SSA & sea salt, $\mathrm{SO}_{4}^{-2}, \mathrm{NO}_{3}^{-}, \mathrm{H}_{2} \mathrm{O}$ & $\mathrm{EM} / \mathrm{HI}$ \\
\hline sea salt coarse mode & SSC & sea salt, $\mathrm{SO}_{4}^{-2}, \mathrm{NO}_{3}^{-}, \mathrm{H}_{2} \mathrm{O}$ & $\mathrm{EM} / \mathrm{HI}$ \\
\hline organic carbon $(\mathrm{OC})$ & $\mathrm{OCC}$ & $\mathrm{OC}, \mathrm{SO}_{4}^{-2}, \mathrm{NO}_{3}^{-}, \mathrm{H}_{2} \mathrm{O}$ & $\mathrm{EM} / \mathrm{HI}$ \\
\hline Black carbon (BC) ( $\leq 5 \%$ inorg.) & $\mathrm{BC} 1$ & $\mathrm{BC}, \mathrm{SO}_{4}^{-2}, \mathrm{NO}_{3}^{-}, \mathrm{H}_{2} \mathrm{O}$ & $\mathrm{EM} / \mathrm{HI}$ \\
\hline BC (5-20\% inorg.) & $\mathrm{BC} 2$ & $\mathrm{BC}, \mathrm{SO}_{4}^{-2}, \mathrm{NO}_{3}^{-}, \mathrm{H}_{2} \mathrm{O}$ & $\mathrm{EM} / \mathrm{HI}$ \\
\hline $\mathrm{BC}(>20 \%$ inorg.) & $\mathrm{BC} 3$ & $\mathrm{BC}, \mathrm{SO}_{4}^{-2}, \mathrm{NO}_{3}^{-}, \mathrm{H}_{2} \mathrm{O}$ & HI \\
\hline $\mathrm{BC}-\mathrm{OC}$ & $\mathrm{BOC}$ & $\mathrm{BC}, \mathrm{OC}, \mathrm{SO}_{4}^{-2}, \mathrm{NO}_{3}^{-}, \mathrm{H}_{2} \mathrm{O}$ & $\mathrm{HI}$ \\
\hline BC-sulfate (formed by coagulation) & $\mathrm{BCS}$ & $\mathrm{BC}, \mathrm{SO}_{4}^{-2}, \mathrm{NO}_{3}^{-}, \mathrm{H}_{2} \mathrm{O}$ & $\mathrm{HI}$ \\
\hline BC-mineral dust & $\mathrm{DBC}$ & dust, $\mathrm{BC}, \mathrm{SO}_{4}^{-2}, \mathrm{NO}_{3}^{-}, \mathrm{H}_{2} \mathrm{O}$ & $\mathrm{HI}$ \\
\hline mixed & MXX & dust, sea salt, $\mathrm{BC}, \mathrm{OC}, \mathrm{SO}_{4}^{-2}, \mathrm{NO}_{3}, \mathrm{H}_{2} \mathrm{O}$ & HI \\
\hline
\end{tabular}

requires additional information about the shapes of the individual aerosol size distributions. We assume a lognormal distribution with constant width when calculating the initial size distributions, the conversion between aerosol mass and number concentration, emission distributions, coagulation rates and aerosol optical properties.

For each aerosol population, defined by mixing state and size distribution, the tracked species are number concentration, and mass concentration of sulfate, nitrate, ammonium, aerosol water, black carbon, organic carbon, mineral dust, and sea salt. Here we use the aerosol population setup called "mechanism 1" (BA08), given in Table 1. MATRIX dynamics includes nucleation, new particle formation, particle emissions, gas-particle mass transfer, aerosol phase chemistry, condensational growth, coagulation, and cloud activation.

In this paper the Napari et al. 2002 nucleation scheme is applied, based on classical nucleation theory involving $\mathrm{H}_{2} \mathrm{SO}_{4}, \mathrm{NH}_{3}$ and $\mathrm{H}_{2} \mathrm{O}$. The conversion from nucleation rate to new particles formation follows BA08. Coagulation can take place among all aerosol populations. Condensational growth is kinetically calculated for $\mathrm{H}_{2} \mathrm{SO}_{4}$ deposition on all particle surfaces, and equilibrium is assumed between $\mathrm{H}_{2} \mathrm{O}$, $\mathrm{NH}_{3}$ and $\mathrm{HNO}_{3}$. The thermodynamic EQSAM model (Metzger et al. 2006) is used to partition the total $\left[\mathrm{NH}_{3}\right]+[\mathrm{NH}+4]$ and total [HNO3]+[NO-3] between the gas and condensed phase, and to obtain the liquid aerosol water concentration.Water uptake by sea salt aerosolis calculated after Lewis (2006).
New additions to BA08 are linking the aerosol scheme to a recent aerosol indirect effect scheme (see Sect. 2.1)and the coupling of mixed aerosol populations to the radiation scheme as described in Sect. 2.2.

\subsection{Aerosol cloud coupling}

To simulate the indirect effect, we follow a similar treatment as described in Menon et al. (2010) that includes several changes to the treatment of cloud drop and ice crystal nucleation following the scheme from Morrison and Gettleman (2008). For cloud droplets, we use a prognostic equation to calculate CDNC, based on Morrison and Gettleman (2008) given as

$\frac{d(\mathrm{CDNC})}{d t}=$

Source-Loss(Autoconversion, Contact, Immersion)

The source term includes newly nucleated CDNC and loss terms account for droplet loss through the process of autoconversion (Qaut), contact nucleation and via immersion freezing. The source term is obtained from MATRIX using the scheme of Abdul-Razak and Ghan (2000) that is based on the Köhler theory for multiple external lognormal modes that are composed of internally mixed soluble and insoluble material. For ice crystal concentrations we include both heterogeneous freezing via immersion freezing based on Bigg (1953) and nucleation by deposition/condensation 
freezing from Cooper (1986) following the treatment described in more detail by Morrison and Gettleman (2008). Here, aerosols do not directly affect ice crystal nucleation, except through their interaction with CDNC. The aerosol indirect effect is obtained from the change in net (shortwave + longwave) cloud radiative forcing and may also be estimated from changes in net TOA radiation.

\subsection{Aerosol radiation coupling}

Previously the GISS radiation scheme treated only externally mixed aerosol populations, suitable for our mass based aerosol scheme (Koch et al. 2006). Here we describe the new coupling scheme for internally mixed aerosol populations. The GISS model radiation scheme (Hansen et al., 1983) includes explicit multiple scattering calculations for solar radiation (shortwave - SW) and explicit integrations over both the SW and thermal (longwave - LW) spectral regions. Gaseous absorbers of $\mathrm{LW}$ radiation are $\mathrm{H}_{2} \mathrm{O}, \mathrm{CO}_{2}, \mathrm{O}_{3}$, $\mathrm{O}_{2}$, and $\mathrm{NO}_{2}$. Size dependent scattering properties of clouds and aerosols are computed from Mie scattering, ray tracing, and T-matrix theory (Mishchenko et al. 1996) to include non-spherical cirrus and dust particles. The k-distribution approach (Lacis and Oinas 1991) utilizes 15 non-contiguous spectral intervals to model overlapping cloud aerosol and gaseous absorption.

The MATRIX module calculates the optical properties single scattering albedo, asymmetry factor and extinction for the 16 aerosol populations for six wavelength bands in the SW and 33 bands in LW and passes those to the GISS modelE radiation code. Each population can include multiple chemical species. If a particle contains only one chemical species, for example a freshly emitted pure organic carbon particle, then the optical properties are those of an externally mixed particle. In those cases MATRIX calculates the refractive index for each population and then uses Mie-code pre-calculated lookup tables in order to assign the corresponding optical parameters. A homogeneous internal mixture is assumed to be a well-mixed particle, most likely containing soluble species including aerosol water. MATRIX calculates the optical properties for those particles by using the volume mixing approach. The following refractive indices at $550 \mathrm{~nm}$ are used in this study: Sulfate (1.528-1.e-7i), nitrate (1.528-1.e$7 i)$, OC (1.527-0.014i), BC (1.85-0.71i), sea salt (1.45-0.i), dust (1.564-0.002i) and water (1.334-3.91e-8i).

\subsection{Model configuration}

Anthropogenic and natural emissions for present day and pre-industrial conditions are taken from the AeroCom project (Dentener et al., 2006 and http://nansen.ipsl.juissieu.fr/ AEROCOM/). We use fluxes for "natural" emissions of dust, sea salt and dimethyl sulfide (DMS), and organic carbon (OC) assuming secondary organic aerosol as a $15 \%$ yield from terpene emissions, and in addition, anthropogenic emis- sions from biomass burning and fossil and bio fuel burning of $\mathrm{SO}_{2}, \mathrm{OC}$ and $\mathrm{BC}$. The inventory provides data for the year 2000 (present-day conditions) and for the year 1750 (preindustrial conditions).

We will discuss direct and indirect aerosol effects by looking at aerosol direct radiative impacts (ADE) and cloud radiative impacts (AIE) at present-day conditions. ADE is calculated by taking the difference between radiative transfer calculations at the top of the atmosphere with and without aerosols. AIE is calculated from changes to the net cloud forcing obtained from differences between total and clear skies for each call to the radiation excluding aerosols. Aerosol direct (ADFC) and indirect radiative flux changes (AIFC) arecalculated as the difference in radiative fluxes between pre-industrial and present day conditions. AIFC and AIE include indirect and semi-direct effects. Semi-direct effects are cloud changes caused by changed vertical heating profiles in the atmosphere caused by aerosol forcing changes.

All radiative flux calculations, ADE, AIE, ADFC and AIFC, are calculated in the aerosol-cloud coupled model, and therefore internal climate feedbacks impact all radiative flux calculations. Note that we do not use the terminology radiative forcing as this would require an offline forcing calculation that does not contain climate feedbacks.

Model simulations for present day and pre-industrial conditions only differ by emission levels. The model runs are performed fully interactive therefore aerosol and cloud changes will impact the general circulation. Historic sea surface temperatures are prescribed as boundary conditions. The model is not coupled to the gas-phase ozone chemistry scheme. Off-line fields of oxidants and nitric acid concentrations are provided as input fields from a previous coupled chemistry - aerosol simulation. Off-line ozone fields are provided for forcing calculation in the model radiation scheme. All offline chemistry fields and GHG concentrations are set to present day concentrations.Present day atmospheric conditions, including present day sea surface temperature, are also applied for the pre-industrial emission runs. The model is employed on a horizontal resolution of $4^{\circ} \times 5^{\circ}$ latitude by longitude and 23 vertical layers. The model uses a 30-min time step for all physics calculations. Every model simulation is integrated for 5.5 years, and if not otherwise noted, five-year mean conditions are discussed in this paper.

\section{Effects of chosen particle size for emission}

In order to calculate emission fluxes in microphysical aerosol models, the mass, number concentration and the mixing state of those emissions need to be known. Information about size distributions is very important for particulate emission fluxes such as dust, sea salt and carbonaceous emissions. Usually some size information is provided for dust and sea salt emissions, or interactively calculated in models, but not for carbonaceous aerosols. Current emission inventories, such as 
Bond et al. [2004] or Cooke et al. [1999] provide only mass emission information, so that each modeler has to choose what sizes to assign for carbonaceous emission fluxes. Textor et al [2006] summarized the sizes of the emitted particles as used by 16 different models that participated in the AeroCom study. Mass median diameter ranging from 0.02 to $0.85 \mu \mathrm{m}$ were used for BC and OC emissions. Some AeroCom models used different sizes for fossil and biomass burning sources, and some models emitted $\mathrm{BC}$ and $\mathrm{OC}$ emissions into several size bins. These choices differed greatly among the models; furthermore there is very little information available about actual emission sizes. Bond et al (2006, Table 3.) collected particle size distribution observations at combustion sources from the literature and reported mass median diameters of $0.038-0.32 \mu \mathrm{m}$ for diesel vehicles, $0.02-$ $1.5 \mu \mathrm{m}$ for gasoline vehicles, $0.1-1.3 \mu \mathrm{m}$ for small solid fuel combustors (excluding coal briquettes), such as wood fireplaces or cooking stoves, and $0.05-0.78 \mu \mathrm{m}$ for large stationary sources such as industrial boilers. However these sizes obtained close to emitters may not be appropriate for global model gridbox-scale initial particle sizes.

In order to understand the importance of emission size distribution of carbonaceous particles, we performed a series of sensitivity studies where only the sizes of carbonaceous emissions are varied. The total mass of the emissions is identical between the experiments, but the emitted number concentration varies among the experiments according to the particle size assumptions. Note that those sizes are just the emission sizes, and that aged particle sizes are determined by the subsequent microphysical processes. In our simulations, carbonaceous aerosols grow by roughly a factor of three, through coagulation, condensation and water uptake. We assume that fossil and bio fuel BC and OC emissions enter the atmosphere as external mixtures, entering population $\mathrm{BC} 1$ and $\mathrm{OCC}$, and biomass burning emissions are internally mixed, entering population BOC in our model. However the model is rather insensitive towards this last assumption, as $\mathrm{BC}$ and $\mathrm{OC}$ from biomass burning sources coagulate very quickly even if emitted as external mixtures (not shown here).

The geometric mean emission particle diameters chosen for the single experiments are reported in Table 2. Three sensitivity experiments are performed around the base case simulation (BASE), one experiment with smaller emission sizes (S1) and two experiments with larger emission sizes (S3, S4).The set of experiments covers approximately the range of observed emission sizes.

The design of the sensitivity experiments is rather simple, but analyzing the results is difficult as nearly everything in the aerosol simulation is affected. First we will analyze the differences between the base case BASE and S1, the experiment with the smallest $\mathrm{BC} / \mathrm{OC}$ emission sizes. The largest differences occur in the coagulation calculation. Smaller carbonaceous particles in experiment S1 impact the mixing state and size distribution in all of MATRIX's populations. Size is
Table 2. Emission sizes, geometric mean mass diameters in $[\mu \mathrm{m}]$ of carbonaceous aerosols.

\begin{tabular}{llll}
\hline & $\begin{array}{l}\text { OC [OCC] } \\
\text { fossil \& bio- } \\
\text { fuel }\end{array}$ & $\begin{array}{l}\text { BC } \\
{[\mathrm{BC} 1]} \\
\text { fossil \& bio- } \\
\text { fuel }\end{array}$ & $\begin{array}{l}\text { BC-OC } \\
{[\mathrm{BOC}]} \\
\text { biomass } \\
\text { burning }\end{array}$ \\
\hline S1 & 0.01 & 0.01 & 0.025 \\
BASE & 0.05 & 0.05 & 0.10 \\
S3 & 0.1 & 0.1 & 0.25 \\
S4 & 0.5 & 0.5 & 1 \\
\hline
\end{tabular}

the most important particle property affecting coagulation. The differences in sulfate, $\mathrm{OC}$ and $\mathrm{BC}$ mixing state between BASE and S1 (S1-BASE) are presented in Fig. 1 for present day conditions. Smaller initial OC/BC sizes lead to more coagulation between sulfate and $\mathrm{BC}$. The sulfate coagulation rate to form BCS (a BC-sulfate mixture) increases from 1087 (BASE) to 8655 (S1) Gg/a, leaving less externally mixed sulfate in the system (sulfate ACC and AKK loads decrease from 188 (BASE) to $41 \mathrm{Gg}$ (S1)). Table 3 in BA08 may be consulted to put those budget numbers into perspective. Net sulfate condensation rates are rather similar between the experiments, but the particles on which surfaces condensation happens changes. In BASE most $\mathrm{H}_{2} \mathrm{SO}_{4}$ condenses on ACC, OCC and BOC particles and aqueous phase $\mathrm{H}_{2} \mathrm{SO}_{4}$ condensations within clouds favors ACC and BOC. In S1 most condensation forms sulfates on BOC surfaces. Again leading to more internally mixed particles, due to less condensation of $\mathrm{H}_{2} \mathrm{SO}_{4}$ on pure sulfate (ACC) particles. Changes in $\mathrm{H} 2 \mathrm{SO} 4$ condensation rates also affect sulfate primary particle production, and decreases sulfate nucleation rates $(1800 \mathrm{Gg} / \mathrm{a}$ (BASE), $1168 \mathrm{Gg} / \mathrm{a}(\mathrm{S} 1)$ ), hence changing the size distribution. BC (Fig. 1 row 2) itself favors coagulation with OC for $\mathrm{S} 1$, this however increases the sulfate ratio in the BCS population. So overall sulfate predominantly mixes with $\mathrm{BC}$ and $\mathrm{BC}$ mixes more with $\mathrm{OC}$, leaving fewer externally mixed $\mathrm{OC}$ (OCC) in the atmosphere. Furthermore, the smaller overall $\mathrm{OC} / \mathrm{BC}$ size leads to more coagulation of $\mathrm{OC}$ and $\mathrm{BC}$ with coarse particles. Figure 2 shows the zonal mean $\mathrm{BC}$ mass mixing ratio, the sum over $\mathrm{BC}$ from all $\mathrm{BC}$ containing populations, of the BASE case and the differences between BASE and the size experiments S1, S3 and S4. The total BC mass increases from the BASE case $1195 \mathrm{Gg}$ to $1287 \mathrm{Gg}$ in S1, with all of the increase happening in the Northern Hemisphere. This is caused by the extended lifetime of smaller pollution BC particles and the fact that smaller particles can be transported over larger distances.

Figure 3 presents the differences of experiments $\mathrm{S} 1$ and S3 with BASE. Comparing BASE and S1, AOT increases over the oceans and decreases in biomass burning areas. The aerosol direct effect shows a similar pattern but of opposite 


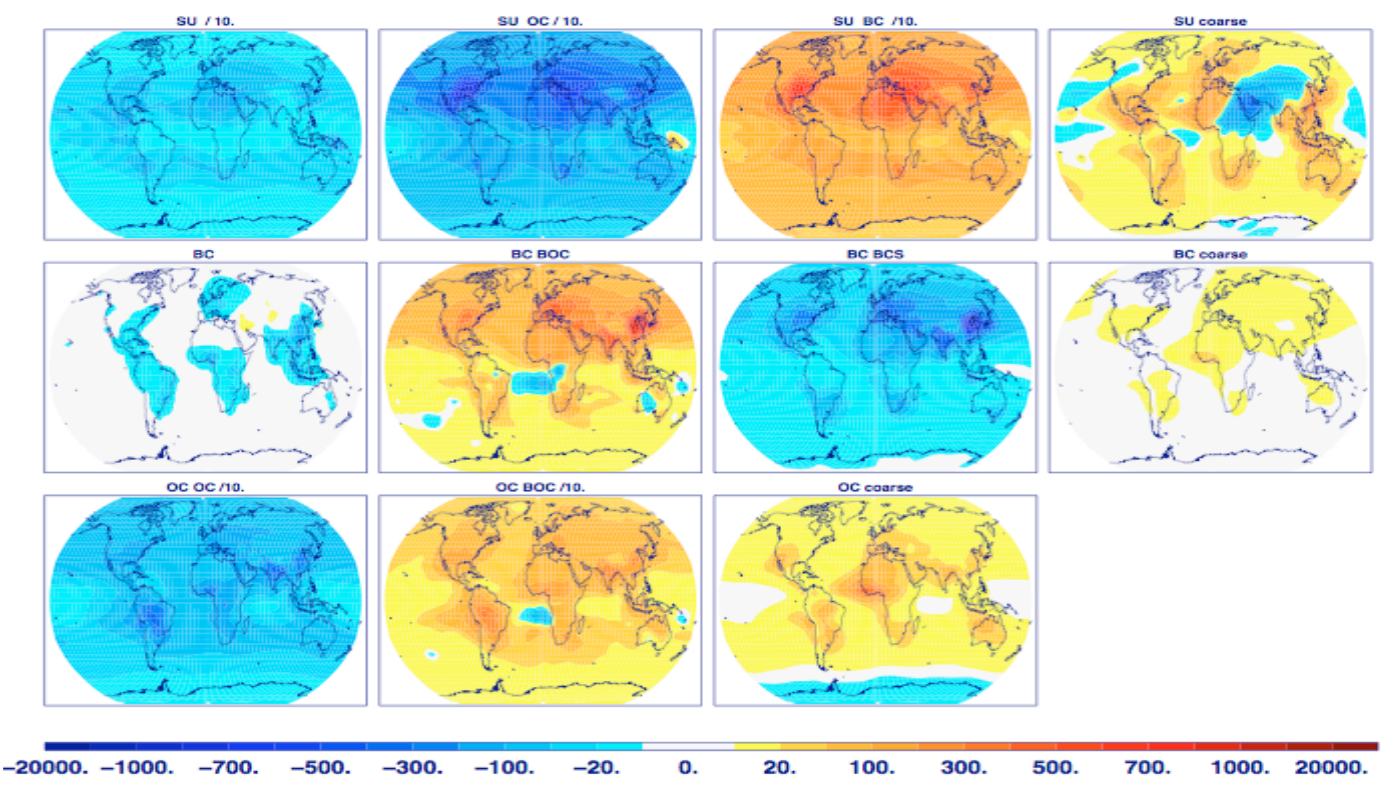

Fig. 1. Differences in present day total column aerosol mass concentrations $\left[\mu \mathrm{g} / \mathrm{m}^{2}\right]$ per mixing state between experiment $\mathrm{S} 1$ and $\mathrm{BASE}$ (S1-BASE). The first row shows externally mixed sulfate (population ACC and AKK), sulfate predominantly mixed with OC (OCC, BOC), $\mathrm{BC}(\mathrm{BC} 1, \mathrm{BC} 2, \mathrm{BC} 3, \mathrm{BCS})$, and sulfate mixed with coarse aerosols (DS1, DS2, SSC, MXX). Rows two and three show the corresponding changes in mixing state for BC and OC mixtures. Graphs show only the sulfate, or BC, OC respectively, mass present in those mixtures. Some aerosol concentrations are divided by a factor of ten to match the color bar as indicated in the individual title of the map.

Table 3. Global annual average values for the net aerosol direct effect (ADE), for sulfate and nitrate (ACC), OC (OCC), BC, sulfate and nitrate (BC-SU, population BC1,BC2,BC3 BCS), BC, sulfate, nitrate and OC (BC-OC, population BOC); AIFC is indirect and semi-direct radiative flux change; $\mathrm{ADFC}$ aerosol direct radiatove flux change and $\mathrm{NR}_{\text {toa }}$ is top of the atmosphere net radiative forcing.

\begin{tabular}{|c|c|c|c|c|c|c|c|c|}
\hline & $\begin{array}{l}\mathrm{ADE}_{\text {toa }} \\
\mathrm{ACC} \\
\mathrm{PD}\end{array}$ & $\begin{array}{l}\mathrm{ADE}_{\text {toa }} \\
\mathrm{OCC} \\
\mathrm{PD}\end{array}$ & $\begin{array}{l}\text { ADE } E_{\text {toa }} \\
\text { BC-SU } \\
\text { PD }\end{array}$ & $\begin{array}{l}\text { ADE } E_{\text {toa }} \\
\text { BC-OC } \\
\text { PD }\end{array}$ & $\begin{array}{l}\mathrm{ADE}_{\text {toa }} \\
\text { total } \\
\mathrm{PD}\end{array}$ & $\begin{array}{l}\text { AIFC } \\
\text { PD-PI }\end{array}$ & $\begin{array}{l}\text { ADFC } \\
\text { PD-PI }\end{array}$ & $\begin{array}{l}\mathrm{NR}_{\text {toa }} \\
\mathrm{PD}-\mathrm{PI}\end{array}$ \\
\hline BASE & -0.05 & \multicolumn{6}{|c|}{ Emission size experiments } & -0.56 \\
\hline S1 & -0.01 & -0.01 & 0.01 & 0.36 & -2.68 & -0.65 & -0.09 & -0.74 \\
\hline S3 & -0.15 & -0.34 & 0.09 & 0.09 & -1.71 & -0.35 & -0.25 & -0.60 \\
\hline S4 & -0.37 & -0.05 & 0.03 & 0.08 & -1.18 & -0.13 & -0.19 & -0.32 \\
\hline
\end{tabular}

sign. ADE increases over land, due to internal mixing of $\mathrm{BC}$ and therefore enhancing overall $\mathrm{BC}$ absorption, which leads to an increase in ADE due to $\mathrm{BC}$ particles. However the dominating feature here is the decreased ADE over the oceans, which is caused by a strong contribution from the mixed population, MXX. The smaller particles in S1 lead to overall more mixing. If all 7 species are mixed together, or none of the other 15 populations can be used, MXX is populated or in other words MXX serves as population for all mixing states that can't fit in any of the other 15 populations. However MXX is always representing a coarse mode as usually some sea salt or dust is present in MXX.
Changes in AIE depend on particle chemistry and number concentrations, and therefore strongly on the size distribution, leading to different changes than seen in the mass concentrations as shown in Fig.1. Regionally the negative AIE (Fig. 3) is caused by the increased cloud droplet number concentration (CDNC) in those regions. Most importantis the shift in size and mixing state. Particles are smaller, but still large enough to activate clouds, and more internally mixed in S1, leading to a larger number of cloud activating particles in polluted sulfate rich regions, but to regional decreases in CDNCs in biomass burning, OC/BC rich regions. In the BASE case CDNCs in biomass burning regions are dominated by externally mixed OC, e.g. OCC, whereas in 

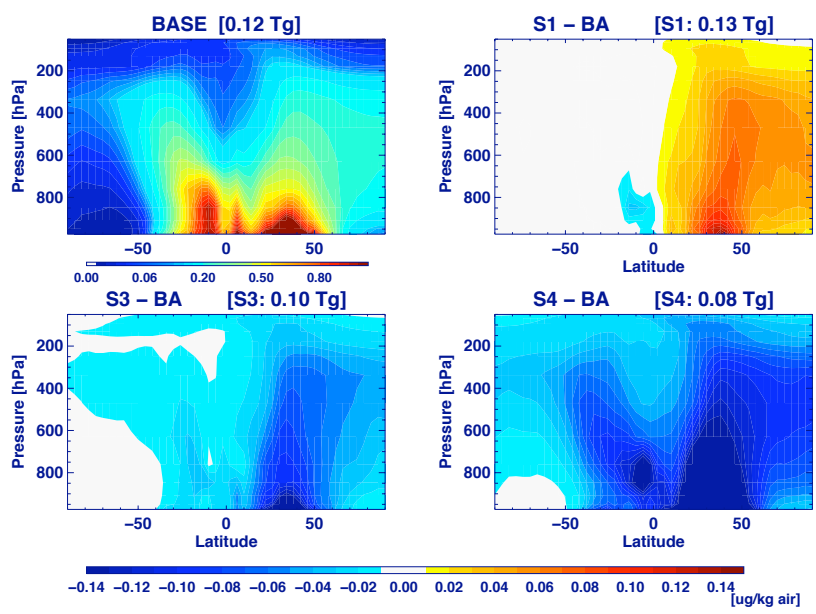

Fig. 2. Zonal mean $B C$ mass mixing $[\mu \mathrm{g} / \mathrm{kg}]$ ratios for the BASE case and the differences between BASE (BA) and the size experiments, S1, S3, and S4. Global mean BC mass concentrations per experiment are given in the figure titles.

S1 more of OC is mixed with BOC leading to overall smaller number concentrations in biomass burning areas. Globally cloud radiative fluxes increase over the oceans leading to a difference of $-0.83 \mathrm{~W} / \mathrm{m}^{2}$ in AIE.

The second set of experiments, S3 and S4, tests the sensitivity of our model at larger BC/OC emission sizes. These experiments show many similarities towards each other, so that it is sufficient here to discuss the results of case S3. Larger initial OC/BC particles lead to less internal mixing of the aerosol populations, leaving more externally mixed sulfate and OC particles. Externally mixed sulfate increases from $188 \mathrm{Gg} / \mathrm{a}$ (BASE) to $575 \mathrm{Gg} / \mathrm{a}(\mathrm{S} 4)$ and more sulfate condenses on coarse particles. Also OC and BC are less mixed with each other, but $\mathrm{BC}$ in the biomass burning regions is more mixed with sulfate, leading again to an increase of sulfate in the BCS population. These changes in mixing state are generally the reverse of case $\mathrm{S} 1$; however this does not translate into a reverse response for the aerosol optics (Fig. 3). AOT globally decreases due to less extinction by the slightly larger and more externally mixed particles. The direct aerosol effect (ADE) relative to BASE is slightly positive, especially in dust regions. This is caused by less coagulation with the overall larger OC/BC/SU particles with dust, hence increasing dust lifetime in S4. The BC load (Fig. 2) is strongly reduced in $\mathrm{S} 3$ to $1041 \mathrm{Gg}$ and $822 \mathrm{Gg}$ in S4.

CDNC particle concentrations are reduced by $-15 \%$ (S3) and $-20 \%$ (S4) leading to a weakened indirect effect, the aerosol indirect effect is approximated from changes to net radiation at the TOA and therefore also includes semi-direct effects, by 3\% (S3) and 4\% (S4); however there was also an increase in liquid water path (LWP) $(0.5 \%$ (S3) and $0.8 \%$ (S4)) and increased cloud cover (1\% (S3) and $0.3 \%(\mathrm{~S} 4))$.
These sensitivity studies showed some surprising sensitivitiesbetween initial carbonaceous particle sizes and CDNC concentrations. The following processes cause CDNC changes:

- Organic carbon is a hygroscopic, potentially cloud activating particle, e.g. assuming smaller/larger particle sizes at emission time will increase the emitted number concentration and eventually lead to higher /lower CDNC.

- Different ambient particle sizes, caused by the different assumption of initial carbonaceous aerosol sizes, impact as well for example sulfate containing particles due to the changes in condensation and coagulation rates among the aerosol populations and impact primary aerosol formation due to the competition for precursor species between the processes of primary aerosol formation and aerosol growth or aging processes.

After discussing the complex interactions a simple summary (Fig. 4) can be given for the impact of carbonaceous aerosol emission sizes on radiative fluxes: Smaller BC/OC emission sizes lead to larger, more negative direct and indirect aerosol effectsand larger $\mathrm{BC} / \mathrm{OC}$ emission sizes to smaller ADE and AIE effects.

\section{Observational constraints}

The experiments performed in this study show large sensitivities of the overall aerosol simulations to the chosen carbonaceous emission. In this section the results of sensitivity experiments are compared to observational datasets, including $\mathrm{BC}$ mass measurements and AERONET (Holben et al., 1998) products.

Table 4 compares the model with the averaged surface BC mass concentrations of the European EMEP (2002-2003) and the North American IMPROVE (1995-2001) network. The base model underestimates European BC concentrations by a factor of 1.6. Decreasing BC emission sizes (S1) improves the simulation, but surface $\mathrm{BC}$ concentrations in $\mathrm{Eu}-$ rope are still too low by a factor of 1.5. The model also underestimates surface BC concentrations in North America by a factor of 1.8, but with improved correlation coefficients compared to the European network. The IMPROVE network includes mainly rural stations and therefore can better be simulated by coarse models, whereas the EMEP network includes more urban stations, that observe more detailed subgrid scale features. Comparing surface observations in polluted regions to a coarse $4^{\circ} \times 5^{\circ}$ model is questionable, but we can conclude that the model underestimates North American and European surface concentrations. The S1 experiment leads to increased and therefore slightly improved surface concentrations in those regions. 


\section{S1- BASE}
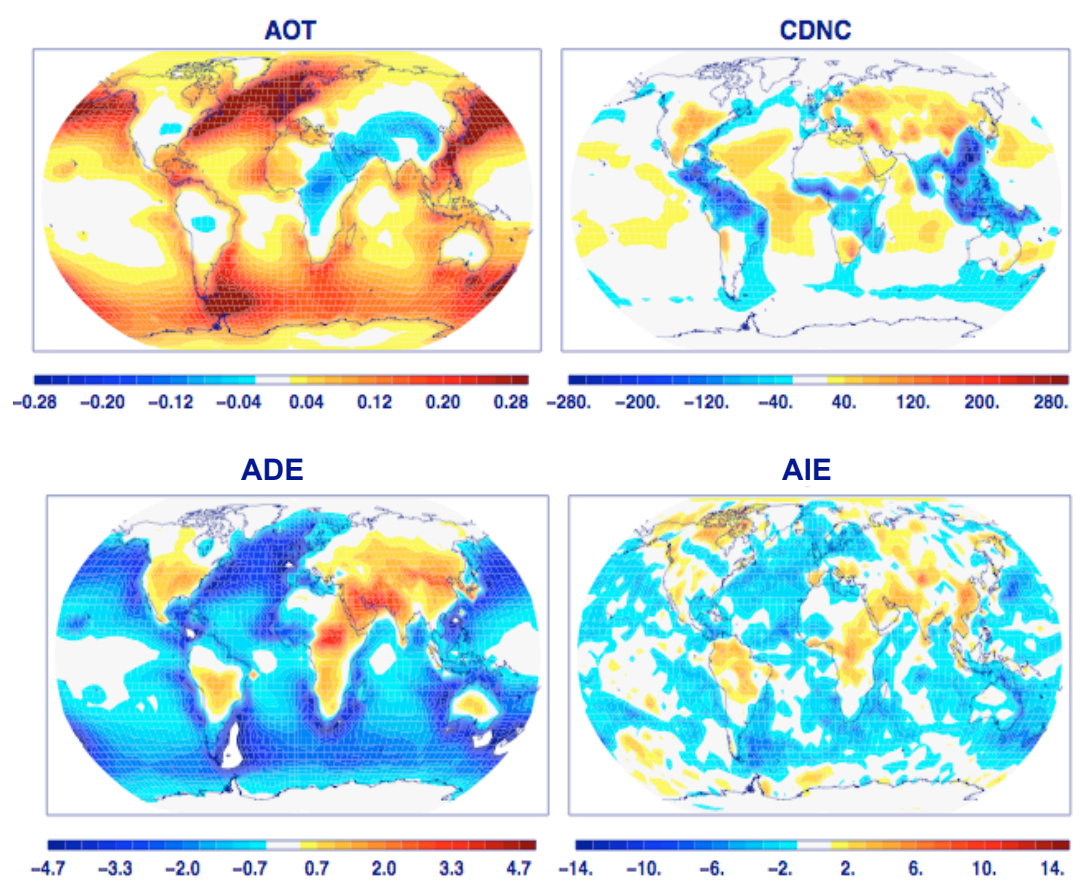

\section{S3 - BASE}
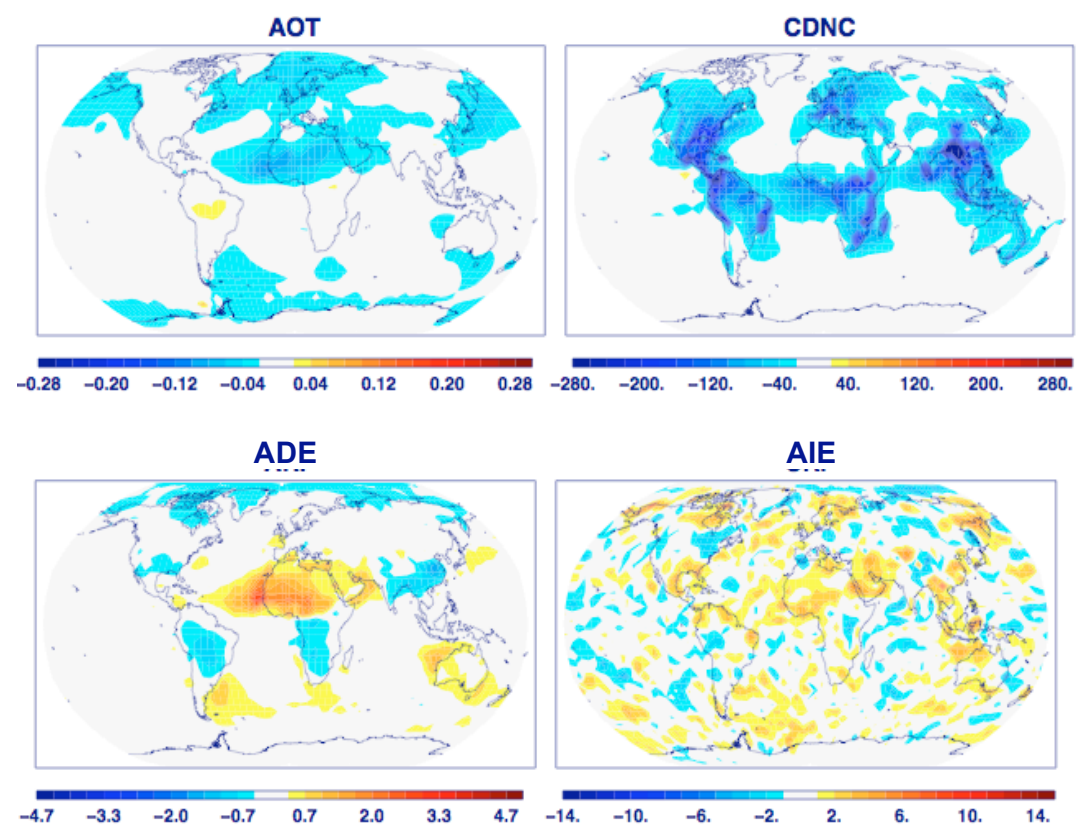

Fig. 3. Changes between BASE and $\mathrm{S} 1$ (S1-BASE) (upper panels) and (S3 - BASE) (lower panels) for AOT, CDNC [\#/cm $\left.{ }^{3}\right], \mathrm{ADE}_{\mathrm{W}} \mathrm{W} / \mathrm{m}^{2}$ ] and AIE $\left[\mathrm{W} / \mathrm{m}^{2}\right]$. All maps show differences between the experiments for present day conditions.

Comparisons between surface concentrations, particularly in regions distant from sources, raise the question of how the $\mathrm{BC}$ is distributed vertically. Figure 2 already demonstrated the large variable of $\mathrm{BC}$ loads among the single experiments.
The causes for the large diversity in aerosol load are the differences in aerosol mixing state, solubility and size distributions, which impacts BC lifetime through wet and dry removal changes and transport. Recent aircraft measurements 
Table 4. Comparison between model simulations and EMEP (EU) and IMPROVE (US) measured surface BC concentrations, and AERONET absorption optical thickness (AAOT) and optical thickness (AOT). Year 2000 AERONET data are used. Model data are averaged at station locations. Gray shadings mark model values that are lower than the observation, red shadings show higher modeled values, and yellow shading indicates best simulation. Global and regional comparisons are presented for, North America, South America, Europe, Africa (including Arabian peninsula) and Asia.

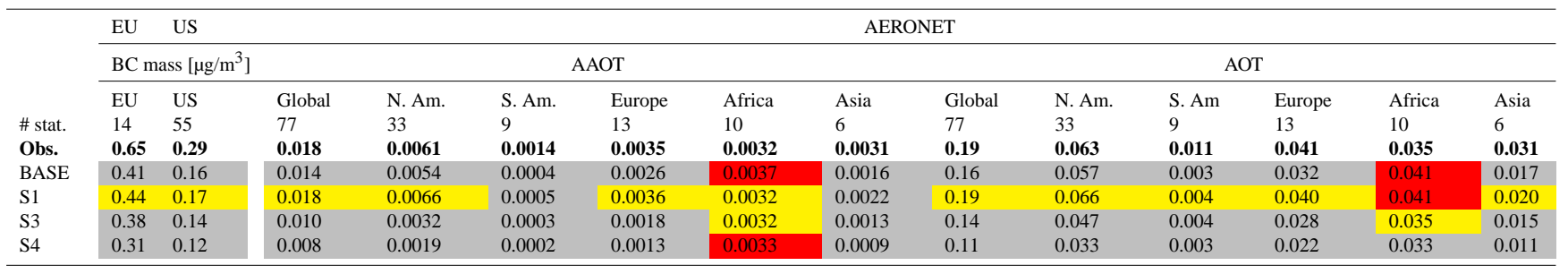

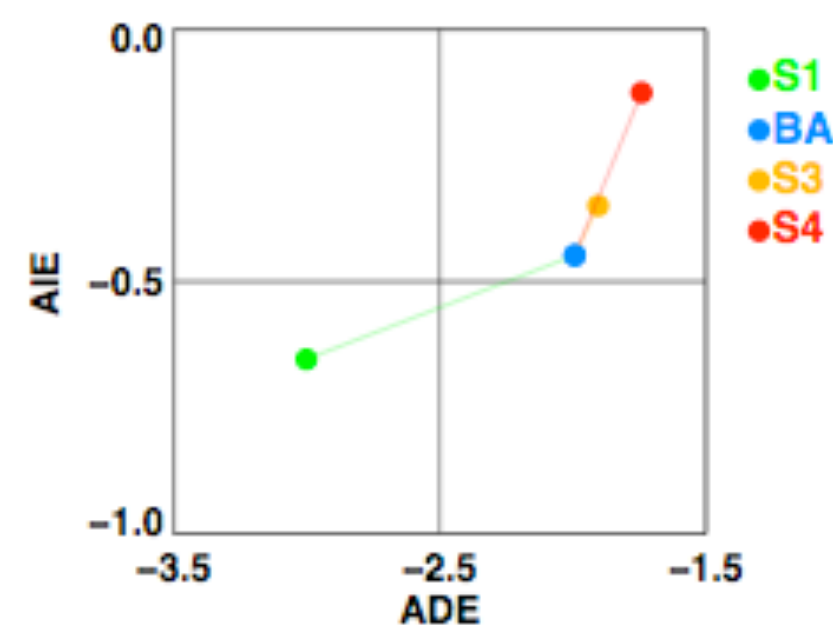

Fig. 4. Global mean AIE and $\mathrm{ADE}\left[\mathrm{W} / \mathrm{m}^{2}\right]$ values for all size experiments, (S1-4) and the base experiment, BA, for present day conditions.

provide BC profile measurements with Single Particle Soot absorption Photometers (SP2) onboard NASA and NOAA research aircrafts (Schwarz et al, 2006; Slowik et al., 2007). In this paper we used the same campaign data and averaging technique as in Koch et al. (2009). Figure 5 shows profiles measured in North American mid-latitude regions (a, d), in the tropics (b,c) and at high latitudes (e-i). The base model simulation generally agrees better with some observed profiles in the mid- and high-latitude regions, overestimates BC concentrations in the tropics and underestimates BC concentrations in some cases at high latitudes. The sensitivity experiments show a rather uniform response globally. Smaller particle size BC/OC emissions (exp. S1) increase the overall $\mathrm{BC}$ mass in the troposphere while larger particles (S3, S4) leads to a decrease. However, no simulation significantly improves the vertical distribution of $\mathrm{BC}$ mass concentrations, as we already get over and underestimations of BC mass concentrations in different latitude regions. Some measurements
( $g$ and $\mathrm{i}$ ) are strongly impacted by biomass burning events, and these instantaneous events are not reflected in the climate model simulation. In summary we dosee some systematic errors in the vertical distribution of $\mathrm{BC}$ (However our regional observational coverage is quite limited.):

- The model overestimates upper-level BC in regions near sources, while surface concentrations in those regions look reasonable.

- The model usually, but not always, underestimates surface $\mathrm{BC}$ in the Arctic.

- The model always fails to reproduce the measured discontinuity (or rapid change) in the vertical distribution in the Arctic.

- Finally, the changes in microphysics do not affect the smoothness of the vertical profile, so microphysics does not explain the model's failure to reproduce the observed sharp discontinuities, however we have to keep in mind that we compare observed snap shots to modeled average mean conditions.

AERONET (Dubovik et al., 2002) observations provide column amounts and absorption of aerosols. These are seasonally averaged for the year 2000. We use the aerosol optical thickness (AOT), which is the most reliable measurement from this network, and the absorption AOT (AAOT), the non-scattering part of the aerosol optical thickness, which involves a higher degree of uncertainty at low AOT conditions.

Figures 6 and 7 show the seasonal comparison between the AERONET data and the base model simulations. The simulation of AOT shows a good seasonal comparison with AERONET. Many seasonal and regional features are well captured. Modeled AOT is underestimated in some megacities, including some European sites and in South America. Table 4. Presents the global as well as regional comparisons of AOT and AAOT. AOT is best simulated in S1. With larger 

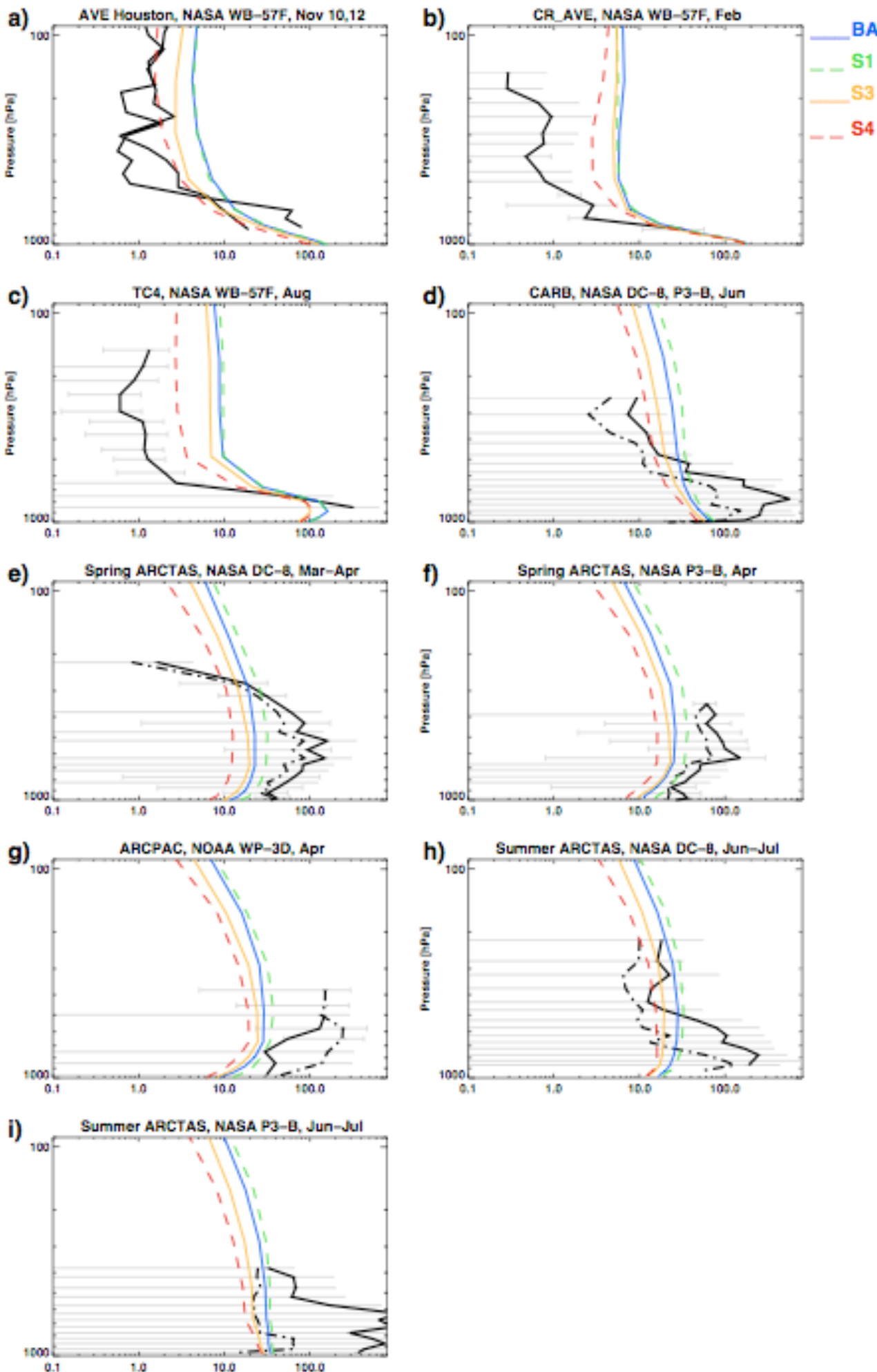

Fig. 5. Modeled (colored) and observed (black lines) BC mass profiles in $[\mathrm{ng} / \mathrm{kg}]$ in the tropics and mid-latitudes (a-d) and ARCPAC and ARCTAS campaign (e-i). Observations are averaged for the respective campaigns, with standard deviations where available. The two black lines in (a) show measurements on two different days. All other profiles give multiple day averages. Mean (solid) and median (dashed) observed pro?les are provided except that (g) theARCPAC campaign has distinct profiles for the mean of the 4 flights that probed long-range biomass burning plumes (dashed) and mean for the flight that sampled aged Arctic air (solid). 

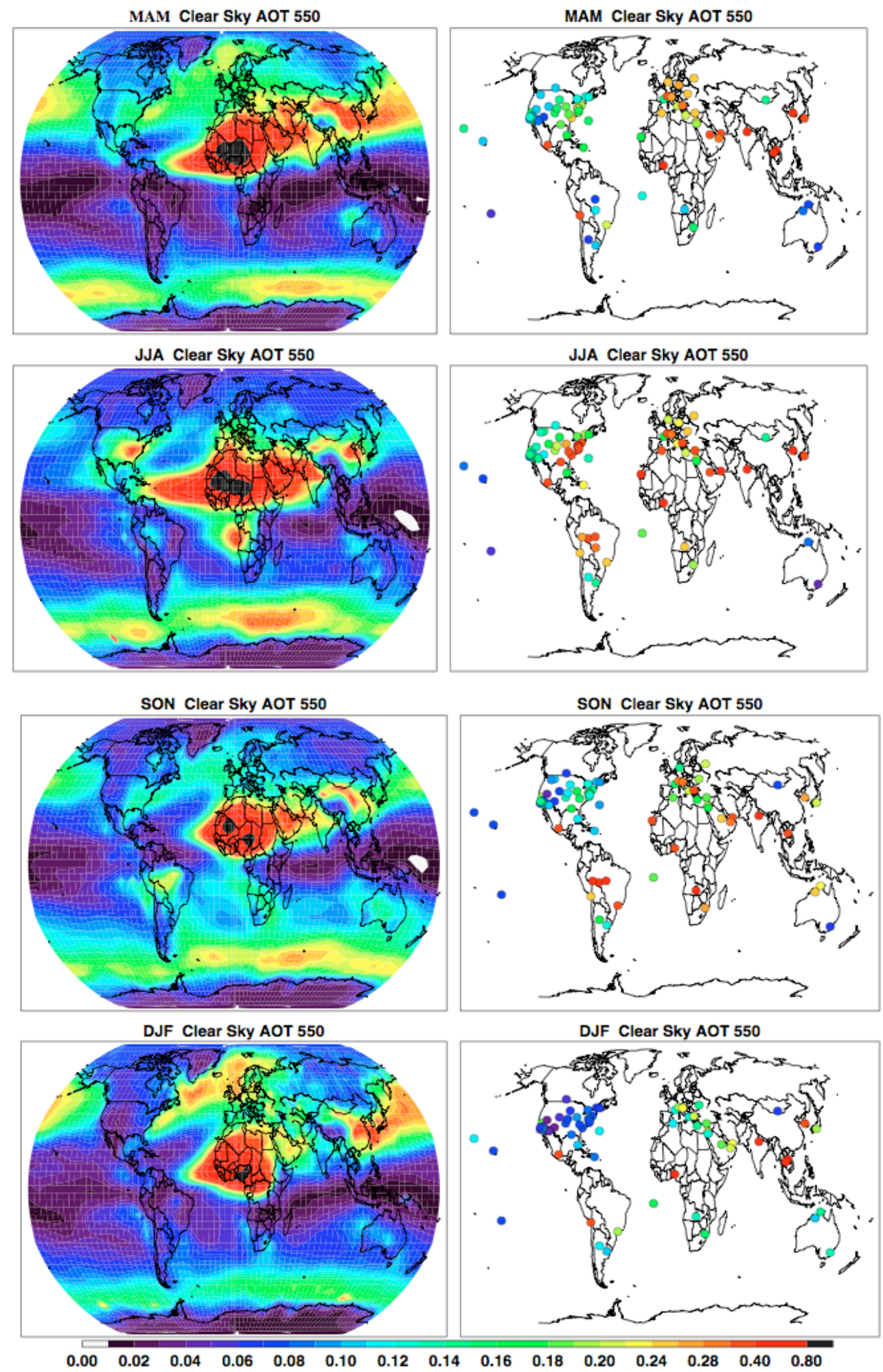

Fig. 6. Aerosol optical thickness at $550 \mathrm{~nm}$ for clear sky conditions shown for the four seasons. Left column shows model data and the filled circles in the right column give the AERONET data. 

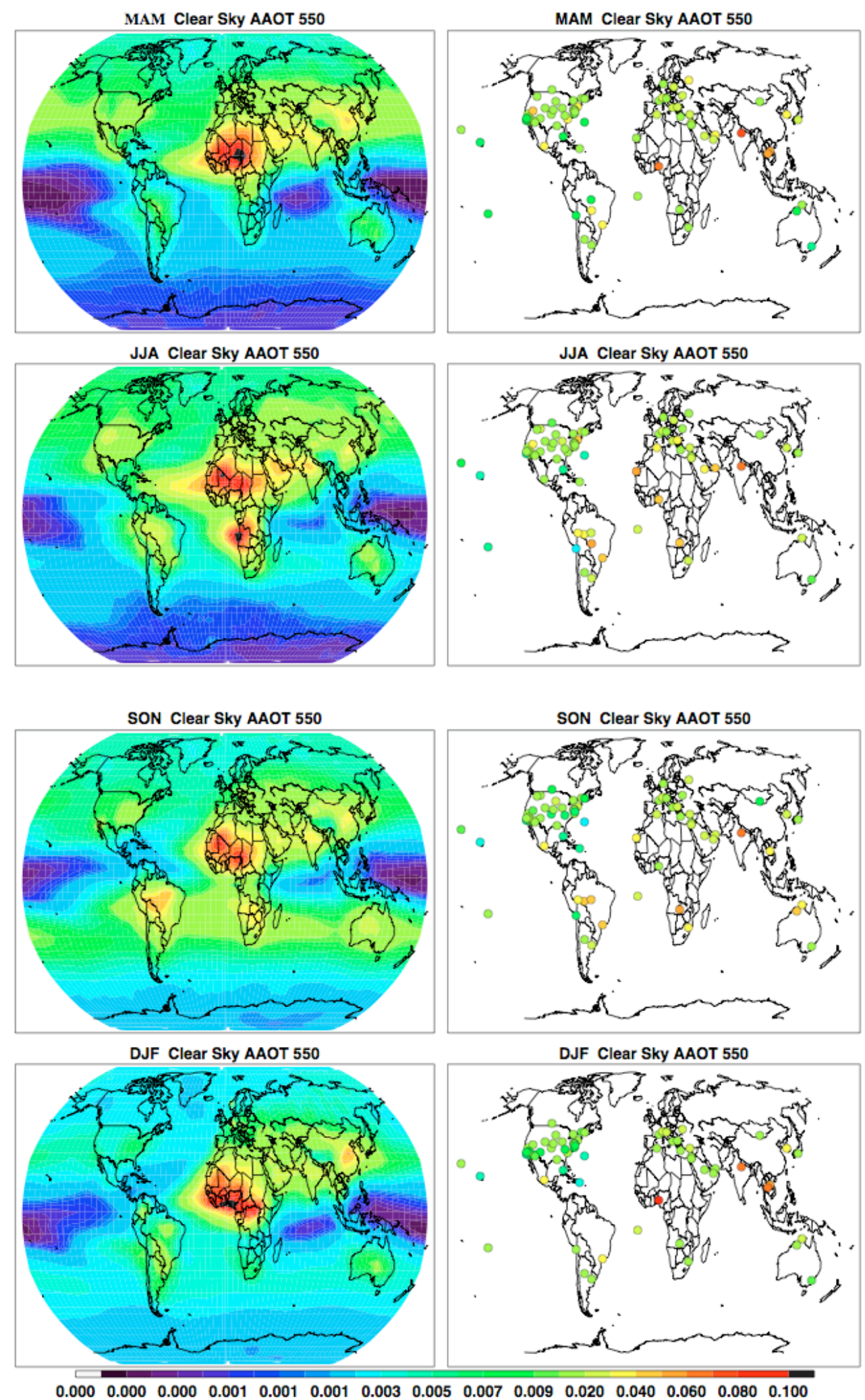

Fig. 7. Aerosol absorption optical thickness at $550 \mathrm{~nm}$ for clear sky conditions shown for the four seasons. Left column shows model data and in the right column AERONET data. 
Table 5. Global mean budgets of the BASE experiment, for present day conditions (PD), differences between PD and PI, and differences between BASE run and BC reduction experiments under PD conditions. The following variables are listed: Non-biomass burning BC and OC emissions, $(\otimes$ Biomass burning emissions are $3 \mathrm{Tg} / \mathrm{a} \mathrm{BC}$ and $24.8 \mathrm{Tg} / \mathrm{a}$ OC for present-day and $1 . \mathrm{T} / \mathrm{g} \mathrm{BC}$ and $9.1 \mathrm{Tg} / \mathrm{a} \mathrm{OC}$ for pre-industrial times), $\mathrm{CDNC}\left(\mathrm{cm}^{3}\right)$, Liquid water path $\left[\mathrm{mg} / \mathrm{m}^{2}\right]$, total cloud cover [\%], the indirect and semi-direct effect (AIE), aerosol direct effect (ADE) at the surface and TOA, and total net radiative change $(\mathrm{NR})\left[\mathrm{W} / \mathrm{m}^{2}\right]$.

\begin{tabular}{|c|c|c|c|c|c|c|c|c|c|}
\hline & $\begin{array}{l}\text { BC1 Emis- } \\
\text { sion } \\
{[\mathrm{Tg} / \mathrm{a}]}\end{array}$ & $\begin{array}{l}\text { OCC } \\
\text { Emission } \\
{[\mathrm{Tg} / \mathrm{a}]}\end{array}$ & $\mathrm{CDNC}\left[\mathrm{cm}^{3}\right]$ & $\mathrm{LWP}\left[\mathrm{mg} / \mathrm{m}^{2}\right]$ & Cloud Cover $[\%]$ & $\begin{array}{l}\mathrm{AIE}_{\mathrm{TOA}} \\
{\left[\mathrm{W} / \mathrm{m}^{2}\right]}\end{array}$ & $\begin{array}{l}\mathrm{ADE}_{\mathrm{TOA}} \\
{\left[\mathrm{W} / \mathrm{m}^{2}\right]}\end{array}$ & $\begin{array}{l}\mathrm{NR}_{\mathrm{TOA}} \\
{\left[\mathrm{W} / \mathrm{m}^{2}\right]}\end{array}$ & $\begin{array}{l}\mathrm{ADE}_{\mathrm{SURF}} \\
{\left[\mathrm{W} / \mathrm{m}^{2}\right]}\end{array}$ \\
\hline BASE (PD) & 4.6 & 22.1 & 162 & 702 & 60.1 & & -1.78 & -1.75 & -4.62 \\
\hline $\begin{array}{l}\text { BASE } \\
(\mathrm{PD}-\mathrm{PI})^{\otimes}\end{array}$ & 0.4 & 14.6 & 41 & 7.0 & 0.2 & -0.45 & -0.11 & -0.56 & -1.32 \\
\hline \multicolumn{10}{|c|}{ Mitigation experiments: Delta between experiment and BASE, (EXP-BASE) } \\
\hline BC_50 (PD) & -2.3 & 0 & 4 & -0.2 & -0.05 & 0.12 & -0.15 & -0.03 & 0.13 \\
\hline $\mathrm{BCFF}(\mathrm{PD})$ & -3.0 & 0 & 3 & -0.43 & -0.07 & -0.05 & -0.15 & -0.20 & 0.20 \\
\hline $\mathrm{BCOCBF}(\mathrm{PD})$ & -1.6 & -6.4 & -5 & -2.52 & -0.14 & 0.20 & -0.07 & 0.13 & 0.21 \\
\hline BC_diesel(PD) & -1.3 & -0.4 & 2 & 0.98 & 0 & -0.05 & -0.05 & -0.10 & 0.11 \\
\hline
\end{tabular}

BC/OC emission sizes, BASE, S3 and S4 AOT gets further underestimated.

S1 shows as well the best simulation of AAOT. Modeled AAOT values are systematically too low in South America and Asia in all experiments. However, AOT was already too low in South America and Asia and therefore the AAOT values can't be evaluated in those two regions.

The model simulates AOT and AAOT in the strongly dust influenced regions of Africa and the Arabian Peninsula best in experiments $\mathrm{S} 3$.

In summary, BC surface concentrations are systematically underestimated in Europe and the US, but the vertical distribution over the North American continent do not show a systematic bias. Aerosol optical measures, such as AOT and AAOT, are fairly well simulated, and improve with the assumption of smaller BC particles, which results in larger BC loads and more internal mixing. Larger $\mathrm{BC}$ particles (experiments S3 and S4) worsen the simulation. Mineral dust is an important absorber and also impacts the comparisonsin this study, but we have not carefully examined these effects here.

\section{Black carbon reduction experiments}

Recently, attention has been drawn towards black carbon aerosols as a short-term climate warming mitigation candidate. Although the $\mathrm{BC}$ direct effect is definitely warming, there remains high uncertainty in estimates of indirect (cloud) changes associated with reductions, due to the complex nature of aerosol evolution and its climate interactions. Furthermore, BC emission reductions must be achieved by controlling individual sources.Therefore co-emitted, cooling species would be reduced as well. Here we conduct two idealized experiments where we simply reduce $\mathrm{BC}$ emissions from fossil and biofuel burning by $50 \%$ (BC_50), and a scenario where $\mathrm{BC}$ fossil fuel emissions are reduced by $100 \%$
(BC_BCFF). Because OC is not reduced, these experiments evaluate the net effect of $\mathrm{BC}$ but not of individual sources.

We also test two more realistic cases where both $\mathrm{OC}$ and $\mathrm{BC}$ from biofuel sources are reduced by 50\% (BCOCBF), and a scenario where $\mathrm{BC}$ and $\mathrm{OC}$ emissions from on-road and off-road diesel were removed (BC_diesel). Particles emitted from diesel engines have the highest $\mathrm{BC}$ fraction of any major source, and the OC:BC ratio of 2:1 is common to all engines. Thus, BC_diesel reflects the likely impact of any control strategy that reduces diesel emissions, although it does not account for reductions in sulfur emissions which would be required to implement advanced controls. On the other hand, biofuel sources have different $\mathrm{OC}: \mathrm{BC}$ ratios, ranging from 3:1 or 4:1 for wood cooking stoves to $6: 1$ for fireplaces or cooking with animal waste. The average OC:BC reduction of 5.6:1 in the BCOCBF case provides an estimate of the response to reductions in high-OC sources, but may not exactly reflect the impact of individual sources. See Table 5 for emission budgets.

The $\mathrm{BC}$ reduction experiments are performed under present day conditions and are compared to PD to PI changes of the BASE experiment. In addition to the fuel emissions, biomass burning emissions for PD runs are $3 \mathrm{Tg} / \mathrm{a} \mathrm{BC}$ and $24.8 \mathrm{Tg} / \mathrm{a}$ OC. Note that also the non-biomass burning OC emissions levels are reduced in experiment BCOCBF and BC_diesel.

The results of all $\mathrm{BC}$ reduction experiments are summarized in Table 5 and Fig. 8. In all experiments reducing $\mathrm{BC}$ emissions leads to less positive direct aerosol impacts (ADE), with changes ranging from -0.05 to -0.15 $\mathrm{W} / \mathrm{m}^{2}$. BC_50 and BCFF show very similar results for ADE, whereas BCOCBF and BC_diesel show much weaker effects. This is caused in the diesel case by smaller BC emission changes and by a slight decrease in $\mathrm{OC}$ emissions. In the $\mathrm{BCOCBF}$ case some of the negative radiative flux change 
BASE PD - PI

CDNC $\left[\mathrm{cm}^{-3}\right] \quad$ Cloud Cover $* 10[\%] \quad$ AIFC $\left[\mathrm{W} / \mathrm{m}^{2}\right]$
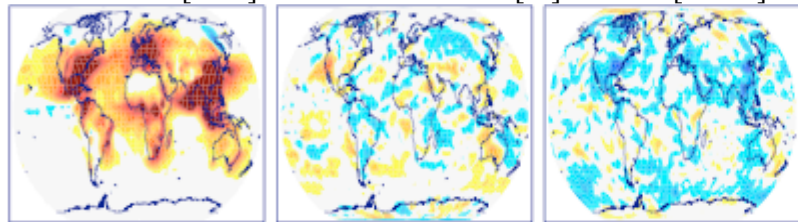

$\mathrm{ADFC}_{\mathrm{TOA}}\left[\mathrm{W} / \mathrm{m}^{2}\right] \quad \mathrm{ADFC}_{\text {surf }}\left[\mathrm{W} / \mathrm{m}^{2}\right]$

BC_50

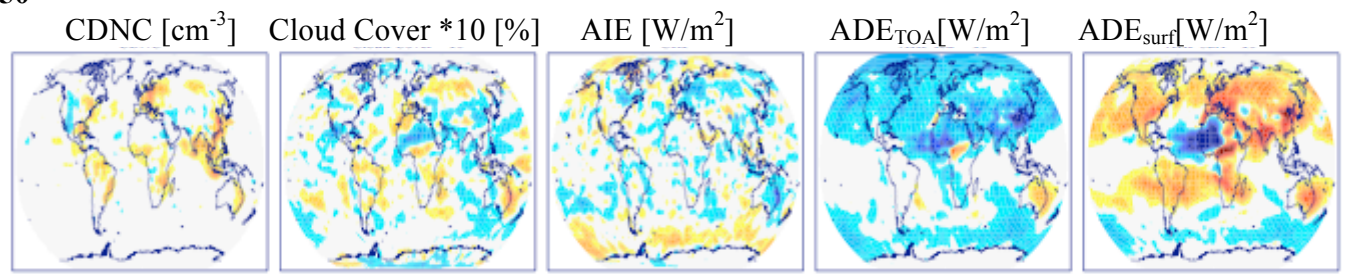

BCFF

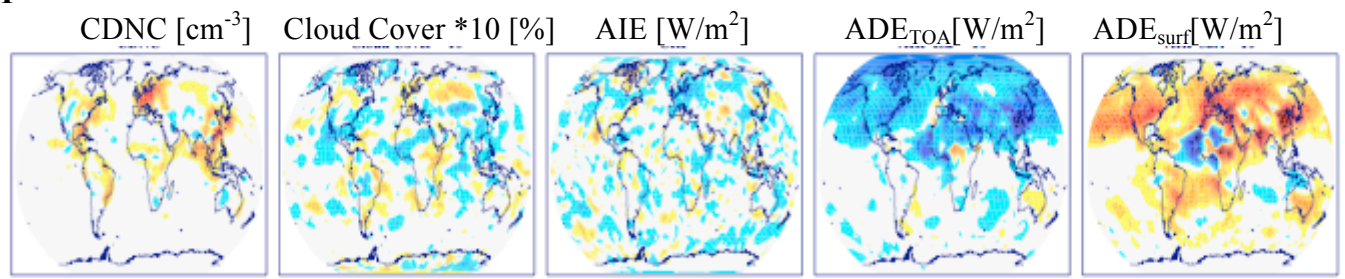

BCOCBF
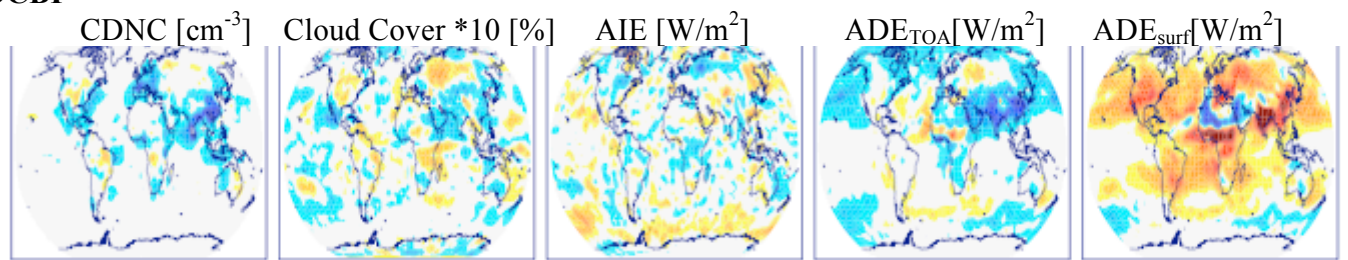

BC_diesel
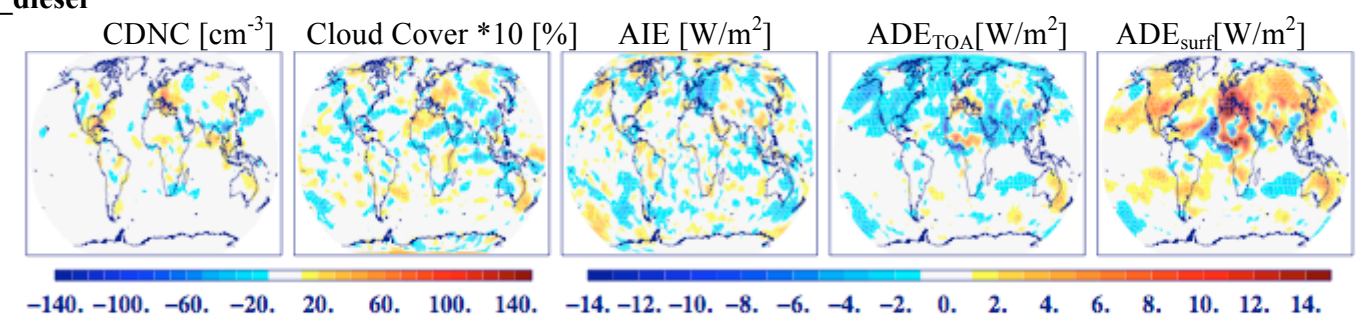

Fig. 8. Differences in CDNC $\left[\mathrm{cm}^{-3}\right]$, total cloud cover [\%], top of the atmosphere cloud (AIE), aerosol (ADE) and surface aerosol radiative flux changes $\left[\mathrm{W} / \mathrm{m}^{2}\right]$, between the PD and PI in the BASE case (first panel) and the difference between BASE and the four BC reduction cases. Cloud cover and ADE are multiplied by a factor of 10 to fit the color scheme.

that is achieved by the $\mathrm{BC}$ emission reduction is counterbalanced by the positive flux change caused by the reduced coemitted OC emissions. In both cases the reduced OC emissions over Europe and the US lead to reduced (BC_diesel) or reversed (BCOCBF) $\mathrm{BC}$ mitigation effects, less positive radiative flux, in those regions, whereas in Asia and the high latitudes both measures would weaken the positive direct aerosol flux.

Table 5 and Fig. 8 also give changes in cloud diagnostics. Reducing $\mathrm{BC}$ emissions leads to a slight increase in CD-
NCs in all experiments, except BCOCBF. Changes to CDNC come from a change in the aerosol mixing state. Reducing the number concentration of $\mathrm{BC}$ particles leads to less internally mixed BC-sulfate particles, and therefore to an increase in the number concentrations of externally mixed sulfate particles, which serve very effectively as CDNC.

First we will discuss the experiments which resulted in reduced CDNCs: BC_50, BCFF, and BC_diesel. Regionally, for example over Europe where the strongest change in CDNCs occurs, more CDNCs lead to an increase in cloud 
cover and therefore to a negative cloud effect. However, globally, even though there are more CDNCs, there is reduction in cloud cover and positive and negative AIEs ranging from 0.11 to $-0.05 \mathrm{~W} / \mathrm{m}^{2}$ per experiment. These cloud cover changes are caused by a competition between indirect and semi-direct effects. Fig. 8 shows the surface radiative flux changes in the single experiments. Reduced BC loads lead to surface heating, due to the missing absorbers in the atmosphere. More radiation can reach and warm the Earth surface, heat the lower atmosphere and lead to a decrease of low-cloud cover and LWP, leading to a positive cloud radiative effect. These semi-direct cloud changes dominate over the smaller cloud changes that result from CDNC enhancement.

Case BCOCBF, where $\mathrm{BC}$ as well as $\mathrm{OC}$ emissions are reduced, shows a decrease of $-5 \%$ in CDNCs. Less CDNCs, leads to reduced LWP and cloud cover and therefore logically to a smaller (less negative) overall cloud effect, resulting in a AIE change of $0.2 \mathrm{~W} / \mathrm{m}^{2}$ compared to the BASE case.

In Summary:

- Reducing BC emissions by 50\% (BC_50) compared to the BASE case leads globally to increased CDNC, decreased cloud cover and LWP and a positive AIE change of $+0.12 \mathrm{~W} / \mathrm{m}^{2}$. Together with the direct aerosol impact of $-0.15 \mathrm{~W} / \mathrm{m}^{2}$ this leads to a net radiative flux difference of $-0.03 \mathrm{~W} / \mathrm{m}^{2}$. In principle we would expect a negative AIE with increased CDNCs. However we see a negative AIE (Fig. 8) in the regions with increased CDNCs, e.g. Europe, South East Asia, Easter US, however the global mean AIE is positive due to positive AIE contributions from remote ocean regions that are not directly impacted by CDNC changes. We speculate, that those changes, e.g. ADE leads to cooling at the surface and TOA over the Southern Hemispheric ocean and positive AIE, are caused by semi-direct effects that are related to aerosol direct impacts.

- Removing fossil fuel emissions (BC_FF) leads as well to an increase in CDNC, decreased cloud cover but an allover negative AIE of $-0.05 \mathrm{~W} / \mathrm{m}^{2}$. Together with the direct aerosol impact of $-0.15 \mathrm{~W} / \mathrm{m}^{2}$ this leads to net radiative flux difference of $-0.2 \mathrm{~W} / \mathrm{m}^{2}$.

- Removing diesel emissions (BC_diesel) still leads to globally increased CDNCs but to a lesser extend than the above discussed cases. India and South East Asia show a decrease in CDNC. Allover this leads to a strong negative AIE over Europe and a global mean AIE of $-0.05 \mathrm{~W} / \mathrm{m}^{2}$. Combined with a negative ADE this results in a net radiative flux difference of $-0.1 \mathrm{~W} / \mathrm{m}^{2}$.

- Reducing biofuel sources (BCOCBF) is the only scenario where we see decreased CDNC concentrations. The strong reduction in $\mathrm{BC}(1.5 \mathrm{Tg} / \mathrm{a})$ and especially OC $(6.4 \mathrm{Tg} / \mathrm{a})$ particles finally resulted in a reduced number concentration of activated particles, which was not the case in the prior discussed scenarios, were the primary emission reduction (BC and $\mathrm{OC}$ ) was only ranging between 1.7 and $3 \mathrm{Tg} / \mathrm{a}$. In this experiment the decrease in primary emission concentration now dominates over the mixing state effects that lead to localized $\mathrm{CDNC}$ increases in regions with moderate $\mathrm{BC}$ reductions. Eventually this leads in the BCOCBF experiment to a positive AIE $+0.2 \mathrm{~W} / \mathrm{m}^{2}$ and a net radiative change flux of $+0.13 \mathrm{~W} / \mathrm{m}^{2}$.

These model experiments show that the success of BC mitigation in reducing positive radiative fluxesdepends on the combination of direct and indirect effects, and the resulting change in the net radiative flux. As a reference, our BASE model estimates a net radiative flux change of $-0.56 \mathrm{~W} / \mathrm{m}^{2}$ for PD-PI. Our simple BC mitigation scenarioswhich ignore co-emitted species, BC_50 and BCFF, show an decrease in the net radiative flux, -0.03 and $-0.2 \mathrm{~W} / \mathrm{m}^{2}$. The two more "realistic" scenarios, BCOCBF and BC_diesel, show that eliminating diesel emissions will also lead to a decrease in the netradiative flux by $-0.1 \mathrm{~W} / \mathrm{m}^{2}$, whereas reducing biofuel sources would increase the positive aerosol radiative effects, due to the combined reduction of $\mathrm{BC}$ and $\mathrm{OC}$ emissions and the resulting reductions in cloud cover. We conclude that the amount of the co-emitted species basically decide whether BC mitigation strategies are increasing or decreasing aerosol related radiative fluxes.

\section{Discussion and conclusions}

In this paper we studied the sensitivity of BC effects on radiative flux changes with a climate model that includes detailed microphysical processes. Since BA08, MATRIX internally and externally mixed aerosol populations are now coupled to the radiation scheme and to cloud indirect effects (SM10). We examined single processes and particle properties and their impacts on cloud and aerosol radiative flux changes. This study allows us to evaluatewhich processes need to be further studied, and what observational data are needed.

First we discussed the importance of initial size distributions for particulate emissions such as BC and OC. Evaluating the model with ambient BC mass and AERONET AOT and AAOT measurements leads to the conclusion that best results are seen when $\mathrm{BC} / \mathrm{OC}$ emission sizes are assumed to be between 0.01 and $0.05 \mu \mathrm{m}$. Aerosol microphysical models such as MATRIX now require particulate emission inventories that include information about aerosol mass, number, surface area, composition, and mixing state, and possibly including subgrid scale effects, such as source-plume mixing, that can not be treated by current climate models.

Koch et al. [2009] showed that the previous generation of aerosol models without aerosol microphysics and mixing 
state influencing optical properties generally underestimate AAOT. In contrast, this study demonstrated a greatly improved agreement with retrieved AAOT, as the internal mixing of $\mathrm{BC}$ enhances absorption. On the other hand, Koch et al. (2009) found that these older models generally did not underestimate $\mathrm{BC}$ surface concentration; the rapid $\mathrm{BC}$ aging of the microphysical scheme in our model caused faster washout near source regions and consequent underestimation of BC surface concentrations. Thus it seems that the microphysics required to improve $\mathrm{BC}$ optical properties has excessively reduced model BC surface concentrations. Careful examination of regional tendencies may help resolve the new discrepancy.

However in order to better understand this behavior we will need to better evaluate the aerosol mixing state simulated by our model. The largest volume fraction is taken up by aerosol water, a quantity that is hardly validated in aerosol models. Chemical and morphological analysis of different individual particles is needed, along with size selective bulk analysis, to understand such processes, taking into account aerosol microphysical processes.

One possible approach to observe mixing state including $\mathrm{BC}$ coating estimates was discussed by Shiraiwa et al. (2008), where the mixing state of BC in Asian air masses was examined by a combination of aerosol mass spectroscopy (AMS) and single-particle soot photometer SP2 data. The AMS data provide a detailed chemical analysis of the measured species, and the SP2 was able to measure the size distribution, and the mixing state of BC. Shiraiwa et al. (2008) found a median value of the shell/core diameter ratio increased to1.6 in Asian continental and maritime air masses with a core diameter of $200 \mathrm{~nm}$, while in free tropospheric and in Japanese air masses it was 1.3-1.4. It was estimated that internal mixing enhanced the $\mathrm{BC}$ absorption by a factor of 1.5-1.6 compared to external mixing. The calculated absorption coefficient was 2-3 times higher in Asian continental air masses than in clean air. A further approach would be the combination of AMS with single particle mass spectroscopy ATOF-MS (Prather et al, 1994), or chemical ionization mass spectroscopy, CIMS (Hearn and Smith, 2004) data. Our ongoing research will focus on the validation of mixing state with these newly emerging datasets.

In light of the analyzed model sensitivities towards microphysical $\mathrm{BC}$ characterization, we performed a set of $\mathrm{BC}$ mitigation studies. The model suggests that $\mathrm{BC}$ mitigation is always beneficial if only $\mathrm{BC}$ sources are reduced, as the direct radiative flux is lowered, and the effects on clouds are weak. BC mitigation led to enhanced CDNC production and a slightly stronger indirect effect; this finding is in contrast to assumptions about reducing primary particle concentrations. However, semi-direct effects, induced by changed vertical heating profiles in the atmosphere, as well as the first and second indirect effect, are very important components of theresponse to altered BC emissions. The two more 'realistic' scenarios which include reduction of OC show that mitigat- ing diesel emissions will decrease aerosol radiative fluxes by $-0.1 \mathrm{~W} / \mathrm{m}^{2}$, whereas reducing biofuel sources could even increase radiative fluxes, mainly due to the impacts on clouds. We can not quantify the forcing uncertainties of the BC reduction experiments, but we want to point out that in light of the large uncertainties already involved with the direct effect, as we discussed in this paper, and the vast complexities of the indirect aerosol effects the uncertainty of the here presented numbers is large.

This study did not include ice cloud feedbacks or BCsnow ice albedo feedbacks (Koch et al. 2009) that may enhance warming by BC. Despite the various limitations explored in this study regarding emission sizes and mixing state of $\mathrm{BC}$ particles, our model results suggest that a reduction in $\mathrm{BC}$ diesel emissions would help reduce positive forcing even when including cloud changes. However, we stress that strategies that include a reduction in BC emissions should not delay any GHG reduction plans, as the likely reductions in positive radiative fluxes from $\mathrm{BC}$ emissions are small and uncertain (from +0.12 up to $-0.19 \mathrm{~W} / \mathrm{m}^{2}$ ) compared to GHG forcings of $2.7 \mathrm{~W} / \mathrm{m}^{2}$ and growing. Furthermore, BC reductions also reduce co-emitted species, many of which have negative forcings, such as OC and sulfate. For sources sufficiently richin black carbon, mitigation is beneficial, but aerosol microphysical processes and their interactions with atmospheric dynamics need to be better constrained in order to estimate climate warming benefits from those measures.

Acknowledgements. This work has been supported by the NASA MAP program Modeling, Analysis and Prediction Climate Variability and Change (NN-H-04-Z-YS-008-N) and (NNH08ZDA001NMAP). KT was supported by an appointment to the NASA Postdoctoral Program at the Goddard Institute for Space Studies, administered by Oak Ridge Associated Universities through a contract with NASA. SM was supported by the US Department of Energy under Contract No. DE-AC02-05CH11231at Lawrence Berkeley National Laboratory and also acknowledges support from the DOE Atmospheric System Research Program and the NASA MAP program. We thank Andy Lacis for never getting tired of explaining the GISS radiation code to us, and Jessica Sagona for her work with the AERONET data sets. We acknowledge AERONET data, available at http://aeronet/gsfc.nasa.gov; IMPROVE data available from http://vista.cira.colostate.edu/IMPROVE; and EMEP data from http://tarantula.nilu.no/projects/ccc. We are acknowledging the aircraft measurements made available to us by groups atNOAA: David Fahey, Ru-shan Gao, Joshua Schwarz, Ryan Spackman, Laurel Watts; University of Tokyo: Yutaka Kondo, Nobuhiro Moteki; and University of Hawaii: Antony Clarke, Cameron McNaughton, Steffen Freitag.

Edited by: M. Kanakidou 


\section{References}

Abdul-Razzak, H. and Ghan, S. J.:A Parameterization of Aerosol Activation. Part 2: Multiple Aerosol Types, J. Geophys. Res., 105, 6837-6844, 2000.

Adams, P. J., and J. H. Seinfeld, Disproportionate impact of particulate emissions on global cloud condensation nuclei concentrations, Geophys. Res. Lett., 30, 1239, doi:10.1029/2002GL016303, 2003.

Bauer, S. E., Wright, D. L., Koch, D., Lewis, E. R., McGraw, R., Chang, L.-S., Schwartz, S. E., and Ruedy, R.: MATRIX (Multiconfiguration Aerosol TRacker of mIXing state): an aerosol microphysical module for global atmospheric models, Atmos. Chem. Phys., 8, 6003-6035, doi:10.5194/acp-8-60032008, 2008.

Bigg, E., The supercooling of water, Meteor. Monogr., 43, 29-32, 1953.

Bond, T., Streets, D., Yarber, K., Nelson, S., Wo, J.-H., and Klimont, Z.: A technology-based global inventory of black and organic carbon emissions from combustion, J. Geophys. Res., 109, D14203, doi:10.1029/2003JD003697, 2004.

Bond T. C., Habib, G., and Bergstrom, R. W.: Limitations in the Enhancement of Visible Light Absorption due to Mixing State, J. Geophys. Res., 111, D20211, doi:10.1029/2006JD007315, 2006.

Bond, T. C. and Sun, H.: Can reducing black carbon emissions counteract global warming?, Environ. Sci. Tech., 39, 5921-5926, 2005.

Cooke, W. F., Liousse, C., Cachier, H., and Feichter, J.: Construction of a 1x1 fossil fuel emission data set for carbonaceous aerosol and implementation and radiative impact in the ECHAM4 model, J. Geophys. Res., 104, 22137-22162, 1999.

Cooper, W.: Ice initiation in natural clouds. Precipitation enhancement - A scientificchallenge, Proc. Phys. Soc. London, 66B, 688-694, 1986.

Dentener, F., Kinne, S., Bond, T., Boucher, O., Cofala, J., Generos, S., Ginoux, P., Gong, S., Hoelzemann, J. J., Ito, A., Marelli, L., Penner, J., Putaud, J.-P., Textor, C., Schulz, M., v. d. Werf, G. R., and Wilson, J.: Emissions of primary aerosol and precursor gases for the years 2000 and 1750 prescribed data-sets for AeroCom, Atmos. Chem. Phys., 6, 4321-4344, doi:10.5194/acp-64321-2006, 2006.

Dubovik, O., Holben, B., Eck, T. F., Smirnov, A., Kaufman, Y., King, M. D., Tanre, D., and Slutsker, I.: Variability of absorption and optical properties of key aerosol types observed in worldwide locations, J. Atmos. Sci., 59, 590-608, 2002.

Hansen, J. E., Russell, G. L., Rind, D., Stone, P., Lacis, A., Ruedy, R., and Travis, L.: Efficient three-dimensional models for climatic studies, Mon. Weather Rev., 111, 609-662, 1983.

Hansen, J., M. Sato, R. Ruedy, L. Nazarenko, A. Lacis, G. Schmidt, G. Russell, I. Aleinov, M. Bauer, S. Bauer, N. Bell, B. Cairns, V. Canuto, Y. Cheng, A. D. Genio, G. Faluvegi, E. Fleming, A. Friend, T. Hall, C. Jackman, M. Kelley, N. Kiang, D. Koch, J. Lean, J. Lerner, K. Lo, S. Menon, R. Miller, P. Minnis, T. Novakov, V. Oinas, J. Perlwitz, J. Perlwitz, D. Rind, D. Romanou, D. Shindell, P. Stone, S. Sun, N. Tausnev, D. Thresher, B. Wielicki, T. Wong, M. Yao, and S. Zhang, Efficacy of climate forcing, J. Geophys. Res, 110, D18104, doi:10.1029/2005JD005776, 2005.

Hansen, J., Mki. Sato, R. Ruedy, A. Lacis, and V. Oinas: Global warming in the twenty-first century: An alter- native scenario. Proc. Natl. Acad. Sci., 97, 9875-9880, doi:10.1073/pnas.170278997, 2000.

Hearn, J. D. and Smith, G. D.: A chemical ionization mass spectrometry method for the online analysis of organic aerosols, Anal. Chem., 76(10), 2820-2826, 2004.

Holben, B. N., Eck, T. F., Slutsker, I., et al.: AERONET - A federated instrument network and data archive for aerosol characterization, Remote Sens. Environ., 66, 1-16, 1998.

Intergovernmental Panel on Climate Change (IPCC) Fourth Assessment Report, Climate Change 2007 Synthesis Report, Contribution of Working Groups I, II and III to the Fourth Assessment Report of the Intergovernmental Panel on Climate Change, 2007.

Jacobson, M. Z.: A physically-based treatment of elemental carbon optics: Implications for global direct forcing of aerosols, Geophys. Res. Lett., 27, 217-220, 2000.

Jacobson, M. Z.: Control of fossil-fuel particulate black carbon and organic matter, possibly the most effective method of slowing global warming, J. Geophys. Res., 107(D19), 4410, doi:10.1029/2001JD001376, 2002.

Khalizov A. F., Xue, H., Wang, L., Zheng, J., and Zhang, R.: Enhanced light absorption and scattering by carbon soot aerosol internally mixed with sulfuric acid, J. Phys. Chem. 113, 10661074, 2009.

Koch, D., Schmidt, G. A., and Field, C. V.: Sulfur, sea salt and radionuclide aerosols in GISS ModelE, J. Geophys. Res., 111, D06206, doi:10.1029/2004JD005550, 2006.

Koch, D., Schulz, M., Kinne, S., McNaughton, C., Spackman, J. R., Balkanski, Y., Bauer, S., Berntsen, T., Bond, T. C., Boucher, O., Chin, M., Clarke, A., De Luca, N., Dentener, F., Diehl, T., Dubovik, O., Easter, R., Fahey, D. W., Feichter, J., Fillmore, D., Freitag, S., Ghan, S., Ginoux, P., Gong, S., Horowitz, L., Iversen, T., Kirkevg, A., Klimont, Z., Kondo, Y., Krol, M., Liu, X., Miller, R., Montanaro, V., Moteki, N., Myhre, G., Penner, J. E., Perlwitz, J., Pitari, G., Reddy, S., Sahu, L., Sakamoto, H., Schuster, G., Schwarz, J. P., Seland, ., Stier, P., Takegawa, N., Takemura, T., Textor, C., van Aardenne, J. A., and Zhao, Y.: Evaluation of black carbon estimations in global aerosol models, Atmos. Chem. Phys., 9, 9001-9026, doi:10.5194/acp-9-9001-2009, 2009.

Lacis, A. A. and Oinas, V.: A description of the correlated k distribution method for modeling nongray gaseous absorption, thermal emission and multiple scattering in vertically inhomogeneous atmospheres. J. Geophys. Res., 96, 9027-9063, 1991.

Lewis, E. R.: The effect of surface tension (Kelvin effect) on theequilibrium radius of a hygroscopic aqueous aerosol particle, J.Aerosol Sci., 37, 1605-1617, 2006.

Lohmann, U., Spichtinger, P., Jess, S., Peter, T., and Smit, H.: Cirrus cloud formation and ice supersaturated regions in a global climate model, Env. Res. Lett., 3, 045022, doi:10.1088/17489326/3/4/045022, 2008.

Morrison, H. and Gettelman, A.: A new two-moment bulk stratiform cloud microphysics scheme in the Community Atmospheric Model (CAM3), Part I: Description and Numerical Tests J. Climate, 21(15), 3642-3659, 2008.

McGraw, R.: Description of aerosol dynamics by the quadraturemethod of moments, Aerosol Sci. Tech., 27, 255-265, 1997.

Metzger, S., Mihalopoulos, N., and Lelieveld, J.: Importance of mineral cations and organics in gas-aerosol partitioning of reactive nitrogen compounds: case study based on MINOS results, 
Atmos. Chem. Phys., 6, 2549-2567, doi:10.5194/acp-6-25492006, 2006.

Menon, S. and Rotstayn, L.: The radiative in?uence of aerosol e? ects on liquidphase cumulus and stratiform clouds based on sensitivity studies with two climate models, Clim. Dynam., 27, 345-356, doi:10.1007/s00382-006-0139-3, 2006.

Menon, S., Koch, D., Beig, G., Sahu, S., Fasullo, J., and Orlikowski, D.: Black carbon aerosols and the third polar ice cap, Atmos. Chem. Phys., 10, 4559-4571, doi:10.5194/acp-10-4559-2010, 2010.

Myhre, G: Consistency between satellite-derived and modeled estimates of the direct aerosol effect, Science, 325, 187-190, 2009.

Mishchenko, M. I., Travis, L. D., and Mackowski, D. W.: Tmatrix computations of light scattering by nonspherical particles: A review, J. Quant. Spectrosc. Radiat. Transfer, 55, 535-575, 1996.

Napari, I., Noppel, M., Vehkamaki, H., and Kulmala, M.: Parametrization of ternary nucleation rate for H2SO4NH3-H2O vapors, J. Geophys. Res., 107(D19), 4381, doi:10.1029/2002JD002132, 2002.

Penner, J. E., Zhang, S. Y., and Chuang, C. C.: Soot and smoke aerosol may not warm climate, J. Geophys. Res., 108 (D21), 4657, doi:10.1029/2003JD003409, 2003.

Prather, K. A., T. Nordmeyer, and K. Salt: Real-Time Characterization of Individual Aerosol-Particles Using Time-Of-Flight MassSpectrometry, Anal. Chem., 66(9), 1403-1407, 1994.

Quaas, J., Ming, Y., Menon, S., Takemura, T., Wang, M., Penner, J. E., Gettelman, A., Lohmann, U., Bellouin, N., Boucher, O., Sayer, A. M., Thomas, G. E., McComiskey, A., Feingold, G., Hoose, C., Kristjánsson, J. E., Liu, X., Balkanski, Y., Donner, L. J., Ginoux, P. A., Stier, P., Grandey, B., Feichter, J., Sednev, I., Bauer, S. E., Koch, D., Grainger, R. G., Kirkevåg, A., Iversen, T., Seland, Ø., Easter, R., Ghan, S. J., Rasch, P. J., Morrison, H., Lamarque, J.-F., Iacono, M. J., Kinne, S., and Schulz, M.: Aerosol indirect effects general circulation model intercomparison and evaluation with satellite data, Atmos. Chem. Phys., 9, 8697-8717, doi:10.5194/acp-9-8697-2009, 2009.

Riemer, N., West, M., Zaveri, R. A., and Easter, R. C.: Simulating the evolution of soot mixing state with a particleresolved aerosol model, J. Geophysical Res., 114, D09202, doi:10.1029/2008/JD011073, 2009.

Schulz, M., Textor, C., Kinne, S., Balkanski, Y., Bauer, S., Berntsen, T., Berglen, T., Boucher, O., Dentener, F., Guibert, S., Isaksen, I. S. A., Iversen, T., Koch, D., Kirkevåg, A., Liu, X., Montanaro, V., Myhre, G., Penner, J. E., Pitari, G., Reddy, S., Seland, Ø., Stier, P., and Takemura, T.: Radiative forcing by aerosols as derived from the AeroCom present-day and pre-industrial simulations, Atmos. Chem. Phys., 6, 5225-5246, doi:10.5194/acp-6-5225-2006, 2006.
Schmidt, G. A., Ruedy, R., Hansen, J., Aleinov, I., Bell, N., Bauer, M., Bauer, S., Cairns, B., Cheng, Y., DelGenio, A., Faluvegi, G., Friend, A., Hall, T. M., Hu, Y., Kelley, M., Kiang, N., Koch, D., Lacis, A. A., Lerner, J., Lo, K. K., Miller, R. L., Nazarenko, L., Oinas, V., Perlwitz, J., Perlwitz, J., Rind, D., Romanou, A., Russell, G. L., Shindell, D. T., Stone, P. H., Sun, S., Tausnev, N., and Yao, M.-S.: Present day atmospheric simulations using giss modele: Comparison to in-situ, satellite and reanalysis data, J. Climate, 19, 153-192, 2006.

Schwarz, J. P., Gao, R. S., Fahey, D. W., Thomsonet, D. S., al.: Single-particle measurements of midlatitude black carbon and lightscattering aerosols from the boundary layer to the lower stratosphere, J. Geophys. Res., 111, D16207, doi:10.1029/2006JD007076, 2006.

Shiraiwa, M., Kondo, Y., Moteki, N., Takegawa, N., Sahu, L. K., Takami, A., Hatakeyama, S., Yonemura, S., and Blake, D. R.: Radiative impact of mixing state of black carbon aerosol in Asian outflow,J. Geophys. Res., 113, D24210, doi:10.1029/2008JD010546, 2008.

Slowik, J. G., Cross, E. S., Han, J. H., et al.: An intercomparison of instruments measuring black carbon content of soot particles, Aerosol Sci. Technol., 41, 295-314, 2007.

Textor, C., Schulz, M., Guibert, S., Kinne, S., Balkanski, Y., Bauer, S., Berntsen, T., Berglen, T., Boucher, O., Chin, M., Dentener, F., Diehl, T., Feichter, J., Fillmore, D., Ginoux, P., Gong, S., Grini, A., Hendricks, J., Horowitz, L., Huang, P., Isaksen, I. S. A., Iversen, T., Kloster, S., Koch, D., Kirkevåg, A., Kristjansson, J. E., Krol, M., Lauer, A., Lamarque, J. F., Liu, X., Montanaro, V., Myhre, G., Penner, J. E., Pitari, G., Reddy, M. S., Seland, Ø., Stier, P., Takemura, T., and Tie, X.: The effect of harmonized emissions on aerosol properties in global models an AeroCom experiment, Atmos. Chem. Phys., 7, 4489-4501, doi:10.5194/acp-7-4489-2007, 2007. 